\title{
Interwell connectivity analysis in a low-permeability formation using a modified Capacitance Model with application to the East Pembina Field, Cardium Formation, Alberta
}

\author{
Mammad Mirzayev*, and Jerry L. Jensen \\ Department of Chemical and Petroleum Engineering, University of Calgary, Alberta, Canada
}

Received: 23 November 2018 / Accepted: 18 December 2018

\begin{abstract}
From the 1950s to the present, the Cardium Formation has been extensively produced. Exploitation has moved from the high-permeability western areas to very heterogeneous lower permeability, "halo-oil" regions in the east. In this case study, we briefly summarize the geology and assess the degree of interwell communication in selected areas from the East Pembina Field. For the Interwell Connectivity (IWC) evaluation, we use a modified version of the Capacitance Model (CM-PW) for connectivity analysis in areal windows. The $\mathrm{CM}$ has been used to analyze flow rates to measure IWC. The direction of the largest IWC change agrees with the expected maximum stress direction in the Western Canada Sedimentary Basin. The model also captures differences between pre- and post-fracturing connectivities. The matches of predicted to measured production using the CM-PW are fair to good, $0.76 \leq R^{2} \leq 0.95$.
\end{abstract}

\section{Nomenclature}

The variables

$\hat{q}(t) \quad$ Predicted total production rate at time step $t$

$q(t) \quad$ Measured total production rate at time step $t$

$q_{j}\left(t_{0}\right) \quad$ Initial total production rate of producer $j$

$q_{p}(\mathrm{t}) \quad$ Pseudo well production rate at time step $t$

$w_{i j}^{\prime}(t) \quad$ Convolved injection rate of injector $i$ at the location of producer $j$ at time step $t$

$w_{i}(t) \quad$ Injection rate of injector $i$ at time step $t$

$p_{w f_{i}}(t)$ BHP of producer $j$ at time step $t$

$w_{p}^{\prime}(t)$ Convolved pseudo well injection rate at time step $t$

$p^{\prime}{ }_{\mathrm{wf}_{k j}}(t)$ Convolved BHP of producer $k$ at the location of producer $j$ at time step $t$

$t_{0} \quad$ Time at the beginning of the window

$t \quad$ Time

Ct Total compressibility, $\left(L t^{2}\right) / \mathrm{m}$

$V_{\mathrm{p}} \quad$ Pore volume, $L^{3}$

I Total number of injection wells

$\mathrm{J} \quad$ Well productivity index, $\left(L^{4} t\right) / \mathrm{m}$
K Total number of production wells

$N \quad$ Total number of samples (time steps) in the analysis period (window)

\section{Greek symbols}

$\tau_{p j} \quad$ Time constant for the primary depletion term

$\lambda_{i j} \quad$ Weight between injector $i$ and producer $j$, indicating the connectivity

$\tau_{i j} \quad$ Time constant for the medium between injector $i$ and producer $j$

$\lambda_{\mathrm{p}} \quad$ Weighting factor for the primary production term

$v_{k j} \quad$ Coefficient for quantifying the effect of the changing BHP of producer $k$

$\tau_{k j} \quad$ Time constant for the medium between producers $k$ and $j$

$\begin{array}{ll}\text { Subscripts and superscripts } \\ i & \text { Injector index } \\ j & \text { Producer index } \\ p & \text { Pseudo well index } \\ k & \text { Producer-BHP index } \\ m & \text { Number of the time step } \\ n & \text { Number of the time step of interest }\end{array}$

\footnotetext{
* Corresponding author: mmir0013@gmail.com
} 


\section{The modified Capacitance Model (Pseudo Well)}

In this paper, we concentrate on analyzing Interwell Connectivity (IWC) changes over small areas (spatial windows) to better understand the effects of well treatments and geology in a low-permeability reservoir. We have already described and evaluated the Capacitance Model with a Pseudo-Well (CM-PW) in an earlier publication (Mirzayev et al., 2017), so we only briefly present its characteristics here.

Applying spatial windowing allows us to study specific areas of interest in detail. Employing the areal windowing technique with the CM-PW, we can choose an injector of interest and offset producers and perform an IWC evaluation. This way we reduce the effects of injection collinearity between nearby injectors. When we apply windowing, however, material balance is no longer preserved, which requires a modification to avoid violating the material balance basis of the original CM. The CM-PW is the CM with a pseudo well in the model, which accounts for any flow imbalance between a chosen area and its outside region and restores material balance in the model.

\subsection{The Capacitance Model and its modifications}

The CM is simple to use for estimating IWC between an injector-producer pair, which requires injection and production data. The CM, nonlinear in the capacitance parameter, provides valuable information about flow trends and barriers in a reservoir. It is a linear reservoir model in connectivities. Noetinger (2016) gives the CM and other connectivity evaluation methods a theoretical foundation and discusses how the governing equations of the $\mathrm{CM}$ can be an effective way to treat complex cases such as hydraulically fractured wells, fracture shear failure and excessive water injection.

The original CM as described by Yousef et al. (2006) has three unknown parameters for each injector-producer pair (Eq. (1)): (1) $\lambda$, showing the magnitude of the connectivity; (2) $\tau$ (time constant), reflecting the fluid storage and compressibility in the interwell region; and (3) v, quantifying the effects of producer BHP variations.

$$
\begin{aligned}
\hat{q}_{j}(t)= & \lambda_{p j} q_{j}\left(t_{0}\right) \mathrm{e}^{-\left(\frac{t-t_{0}}{\tau_{p j}}\right)}+\sum_{i=1}^{i=\mathrm{I}} \lambda_{i j} w_{i j}^{\prime}(t) \\
& +\sum_{k=1}^{k=\mathrm{K}} v_{k j}\left[p_{\mathrm{wf}_{j}}\left(t_{0}\right) \mathrm{e}^{-\left(\frac{t-t_{0}}{\tau_{p j}}\right)}-p_{\mathrm{wf}_{j}}(t)+p_{\mathrm{wf}_{k j}}^{\prime}(t)\right] .
\end{aligned}
$$

A simplification gives the CMP, introduced by Liang et al. (2007). This simplification reduces the number of model parameters by setting $\tau_{i j}=\tau_{j}$ and $\tau_{k j}=\tau_{j}$. That is, there are only two time constants $\left(\tau_{j}\right.$ and $\left.\tau_{p j}\right)$ for each producer. $w_{i j}^{\prime}(t)$ and $p_{\mathrm{wf}_{k j}}^{\prime}(t)$ are defined as

$$
w_{i j}^{\prime}(t)=\sum_{m=1}^{n}\left(\mathrm{e}^{\left(\frac{t_{m}-t}{\tau_{j}}\right)}-\mathrm{e}^{\left(\frac{t_{m-1}-t}{\tau_{j}}\right)}\right) w_{i}\left(t_{m}\right),
$$

and

$$
p_{\mathrm{wf}_{k j}}^{\prime}(t)=\sum_{m=1}^{n}\left(\mathrm{e}^{\left(\frac{t_{m-t}}{\tau_{j}}\right)}-\mathrm{e}^{\left(\frac{t_{m-1}-t}{\tau_{j}}\right)}\right) p_{\mathrm{wf}_{k}}\left(t_{m}\right) .
$$

For spatially windowed case runs, we use the CMP with a pseudo-well, the CM-PW. The CM-PW detects the type of imbalance within the selected area and treats it as a pseudo well. The following interpretation is adapted from Mirzayev et al. (2017).

When the total injection rate of the system exceeds the total production rate, the $\mathrm{PW}$ is a pseudo producer (Eq. (4)).

$$
q_{p}(t)=\left|\sum_{i=1}^{i=\mathrm{I}} w_{i}(t)-\sum_{k=1}^{i=\mathrm{I}} \sum_{k=1}^{k=K} \lambda_{i k} w_{i}(t)\right|
$$

The production rate of the pseudo producer $\left(q_{p}\right)$ is adjusted for the injection-production time delay which, in effect, means the pseudo production well produces from the same locations where injectors are present; therefore, injection rates are not required to be time-shifted for $q_{\mathrm{p}}$. The estimated $\hat{q}_{p}(t)$ equals to

$$
\begin{aligned}
\hat{q}_{p}(t)= & \lambda_{p p} q_{p}\left(t_{0}\right) \mathrm{e}^{-\left(\frac{t-t_{0}}{\tau_{p p}}\right)}+\sum_{i=1}^{i=\mathrm{I}} \lambda_{i p} w_{i p}(t) \\
& +\sum_{k=1}^{k=\mathrm{K}} v_{k p}\left[p_{\mathrm{wf} p}\left(t_{0}\right) \mathrm{e}^{-\left(\frac{t-t_{0}}{\tau_{p p}}\right)}-p_{\mathrm{wf} p}(t)+p^{\prime}{ }_{\mathrm{wf} k p}(t)\right],
\end{aligned}
$$

where $\hat{q}_{p}(t)$ is estimated via optimization. The first term of equation (5) is the remnant of the prior production of the pseudo well for $t<t_{0}$. The second and third terms represent the contribution from the injectors and the effect of possible BHP variations of producers on the pseudo well production rate at time step $t$, respectively.

The PW is called a pseudo injector when there is a flux into a window area. The pseudo injection rate is timeshifted to the production wells, which means the pseudo well injection rate is already filtered (Eq. (6)). When the $\mathrm{PW}$ is an injector, it injects from the same locations where producers are present (Mirzayev et al., 2017):

$$
w_{p}^{\prime}(t)=\left|\sum_{k=1}^{k=\mathrm{K}} q_{k}(t)-\sum_{i=1}^{i=\mathrm{I}} \sum_{k=1}^{k=\mathrm{K}} \lambda_{i k} w_{i k}^{\prime}(t)\right|,
$$

where the weighted $w_{p}^{\prime}$ adds to $\hat{q}_{j}$ :

$$
\begin{aligned}
\hat{q}_{j}(t)= & \lambda_{p j} q_{j}\left(t_{0}\right) \mathrm{e}^{-\left(\frac{t-t_{0}}{\tau_{p j}}\right)}+\sum_{i=1}^{i=\mathrm{I}} \lambda_{i j} w_{i j}^{\prime}(t)+\lambda_{p j} w_{p}^{\prime}(t) \\
& +\sum_{k=1}^{k=\mathrm{K}} v_{k j}\left[p_{\mathrm{wf} j}\left(t_{0}\right) \mathrm{e}^{-\left(\frac{t-t_{0}}{\tau_{p j}}\right)}-p_{\mathrm{wf} j}(t)+p_{\mathrm{wf}_{k j}}^{\prime}(t)\right] .
\end{aligned}
$$

In summary, the algorithm of the model can be presented as in Figure 1. 


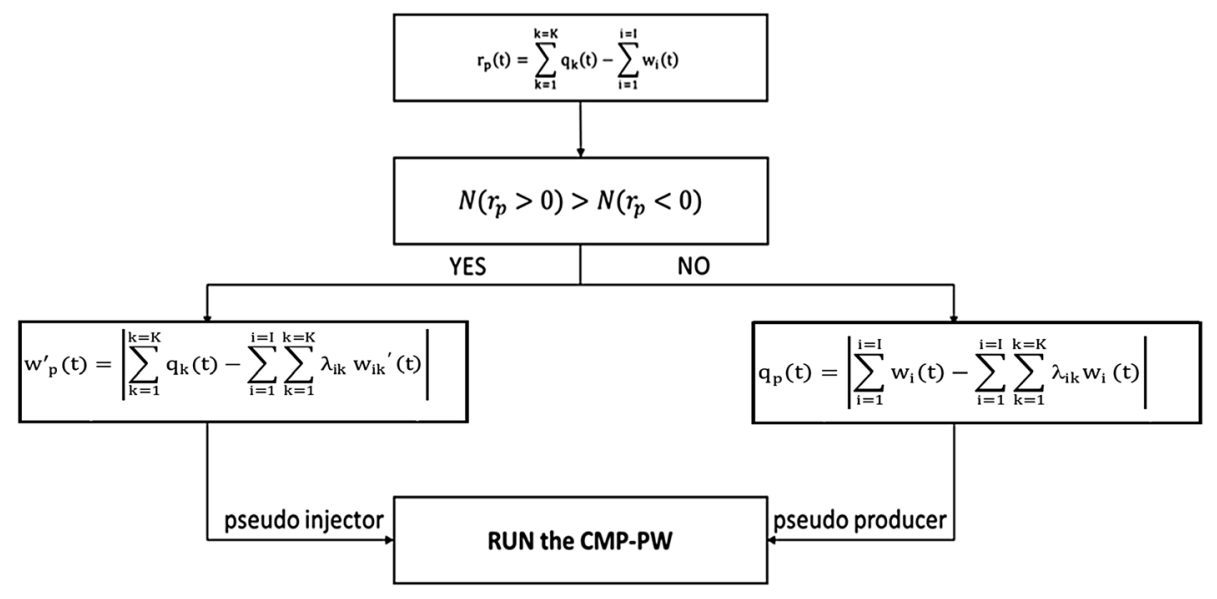

Fig. 1. The algorithm of the CM-PW. $r_{\mathrm{p}}$ is the fluid imbalance at a time in the system.

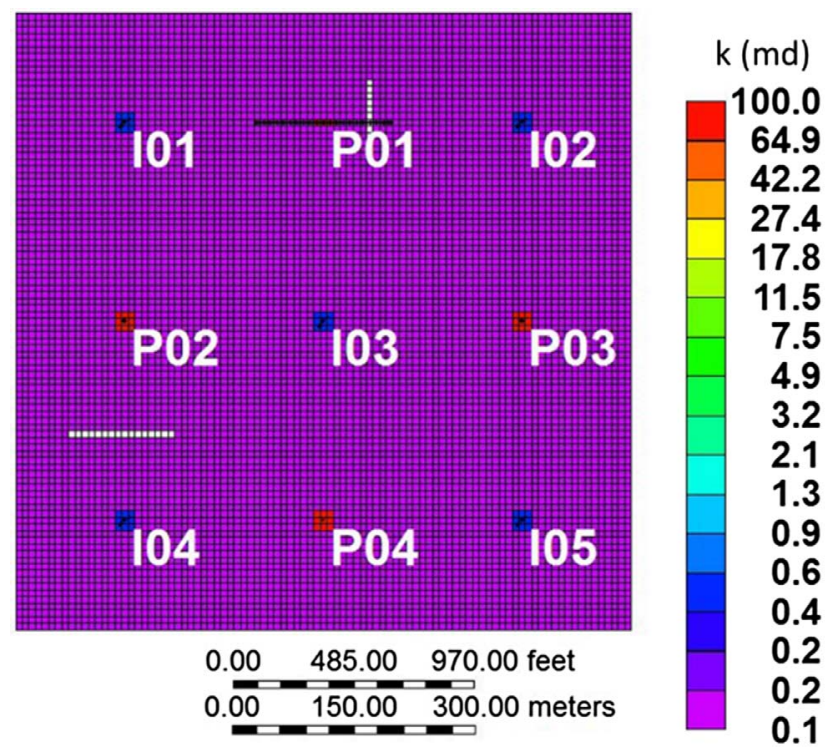

Fig. 2. $5 \times 4$ heterogeneous model with producers stimulated $(-2$ skin $)$ fractured; production and injection wells are denoted by $\mathrm{P}$ and $\mathrm{I}$, respectively.

\subsection{Testing the CM-PW with vertical wells in a low-permeability model}

We tested the model with homogeneous and heterogeneous cases. More details for the homogeneous case are given in Appendix A.

We simulated the production rates from a five-injector and four-producer $(5 \times 4)$ heterogeneous model with matrix permeability of $0.1 \mathrm{md}$ (Fig. 2, Tab. 1) and BHPs constant employing a commercial simulator. The near wellbore region of the producers is modified to represent enhancement due to hydraulic fracturing. Since some of fractured producers were converted to injectors during field development in the East Pembina Field, we also modified the near wellbore regions of injectors to account for the stimulation done prior to conversion. This allows us to inject water with higher injection rates than would ordinarily be the case for
Table 1. Reservoir and fluid data used for the case 1 homogeneous $5 \times 4$ model.

\begin{tabular}{lc}
\hline Parameter & Value \\
\hline Porosity, $\varphi$, fraction & 0.18 \\
Horizontal $k$, md & 0.1 \\
Vertical $k$, md & 0.01 \\
Total compressibility, $c_{\mathrm{t}}, \mathrm{psi}^{-1}$ & $2 \times 10^{-6}$ \\
$\mu_{\text {oil }}, c p$ & 2 \\
$\mu_{\text {water }}, c p$ & 0.5 \\
Reservoir size in $x$-direction, $\mathrm{ft}$ & 2480 \\
Reservoir size in $y$-direction, $\mathrm{ft}$ & 2480 \\
Formation thickness, ft & 27 \\
Reservoir depth, ft & 3000 \\
Reservoir pressure, $\mathrm{psi}$ & 1470 \\
\hline
\end{tabular}

Table 2. P01 hydraulic fracture properties.

\begin{tabular}{lc}
\hline Parameter & Value \\
\hline Primary fracture width, ft & 0.1 \\
Primary fracture permeability, md & 1000 \\
Half length, ft & 275 \\
\hline
\end{tabular}

the East Pembina Field wells. P01 hydraulic fractures pass through the barrier between P01 and I02 (Fig. 2) and the hydraulic fracture properties of P01 are provided in Table 2. There is also another barrier between I04 and P02 (Fig. 2).

The simulation is run for 51 months and the data are sampled quarterly (Fig. 3). The injection rates are created using the actual average and standard deviation values for East Pembina injection wells (Fig. 3a).

When we apply the CM to evaluate IWC for this case, we observed that due to very low permeability, the model only moderately identifies the heterogeneities in the model. For example, the barrier between I04 and P02 only reduces the connectivity by $10 \%$ when compared with the I04-P04 connectivity (Fig. 4). Nonetheless, the model successfully 


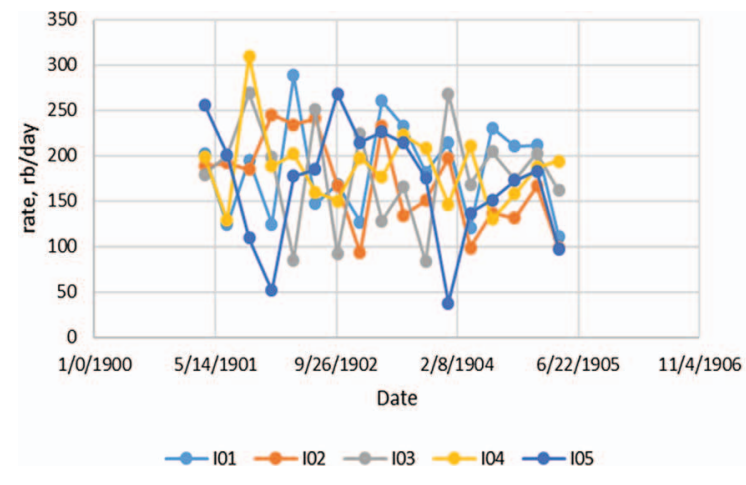

a) injection rates

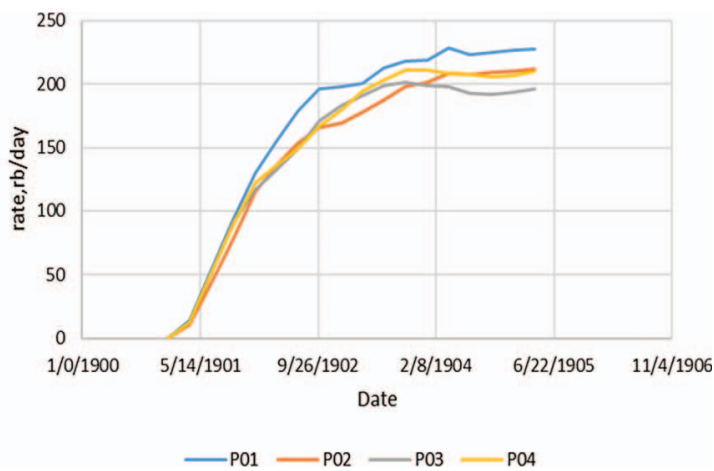

b) production rates

Fig. 3. a) Injection rates; and b) production rates. Rates are sampled quarterly.

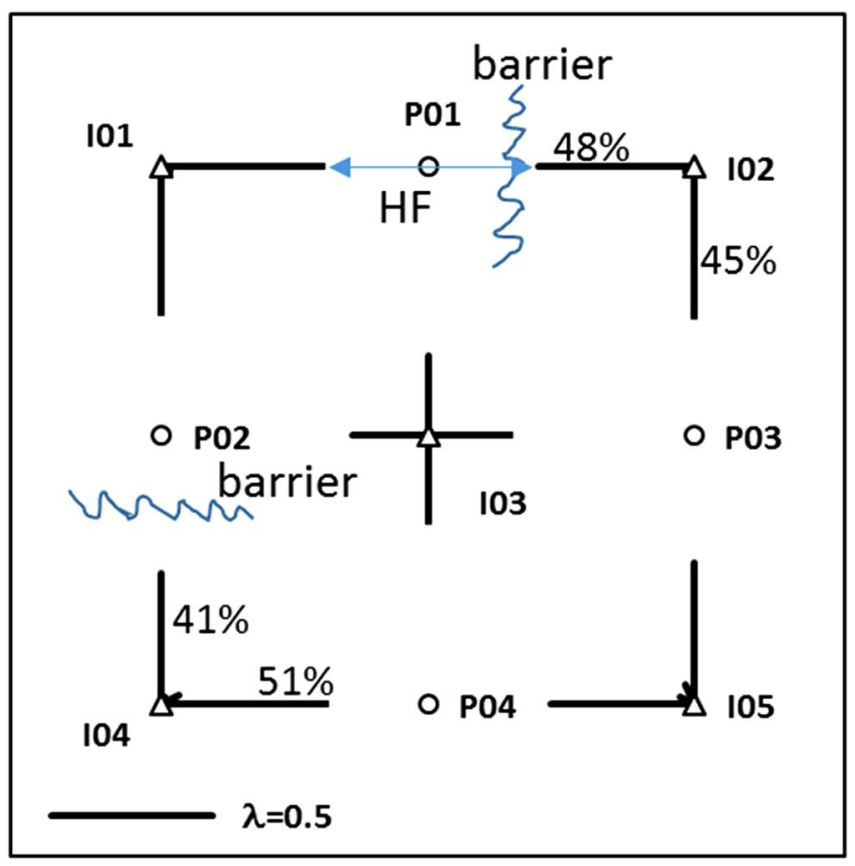

Fig. 4. Connectivity map of the heterogeneous case with matrix permeability of $0.1 \mathrm{md}\left({ }^{*} \mathrm{HF}\right.$ : hydraulic fracture).

predicted the simulated production rates with near-unity $R^{2}$ value (Fig. 5). This shows that the model can evaluate heterogeneities in cases having small matrix permeabilities similar to those in the East Pembina Field.

\section{Cretaceous Cardium Formation and connectivity analyses}

The Cretaceous Cardium Formation was named by Scottish geologist James Hector because of the fossilized cockle (Cardiidae) shells it contains (Braunberger and Hall, 2001). Reservoirs in the Cardium Formation have been found in the depth range of 1200-2700 m (Krause et al., 1994). Neighboring source rocks generated the light and sweet hydrocarbon found in these reservoirs (Krause et al., 1994).

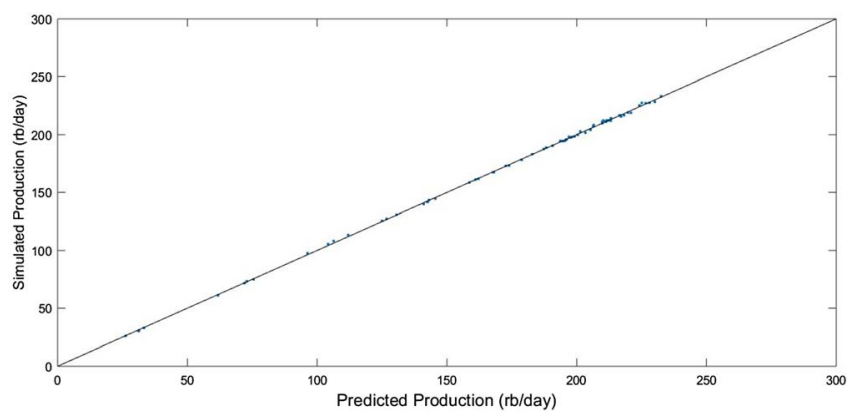

Fig. 5. Simulated vs. CM-PW predicted rates comparison $\left(R^{2}=0.9997\right)$.

The Cardium Formation has been exploited since the 1950s, with exploitation moving from conventional, highpermeability areas to tighter, low-permeability regions. Today, the low permeability eastern deposits of the Cardium Formation have become attractive zones to target as technological advancements (e.g., horizontal wells with multistage fractures) have made it economically viable.

The conglomerate is a major Cardium heterogeneity and is distributed discontinuously. It is seen as one of the most troublesome lithohydraulic units in the reservoir as injected fluids are likely to channel through it, leading to early water breakthrough and small oil recoveries (Gillund, 1969; Kloepfer and Griffith, 1965; Krause et al., 1987).

Sandbody continuity is another major concern for the Cardium Formation. Krause et al. (1987) observed that in their study area, from south-central Pembina Field (T47, R7 W5M) with good core coverage, lithofacies are formed as a mosaic and lack continuity i.e., the labyrinth configuration in the terminology of Weber and van Geuns (1990). Interbedding, lensing, and shingling prevail in lithofacies and lithohydraulic units. Krause et al. (1987) assumed that the lithofacies extend halfway between wells, a distance of approximately $285 \mathrm{~m}$, for their analysis. Butrenchuk et al. (1995) noted that high lateral continuity would be anticipated in the sandstones and shales with their proposed depositional model of a prograding shoreline stepping out into the basin, suggesting a more continuous system (i.e., jigsaw puzzle in the Weber and van Geuns (1990) characterization) than Krause et al. (1987) propose. 


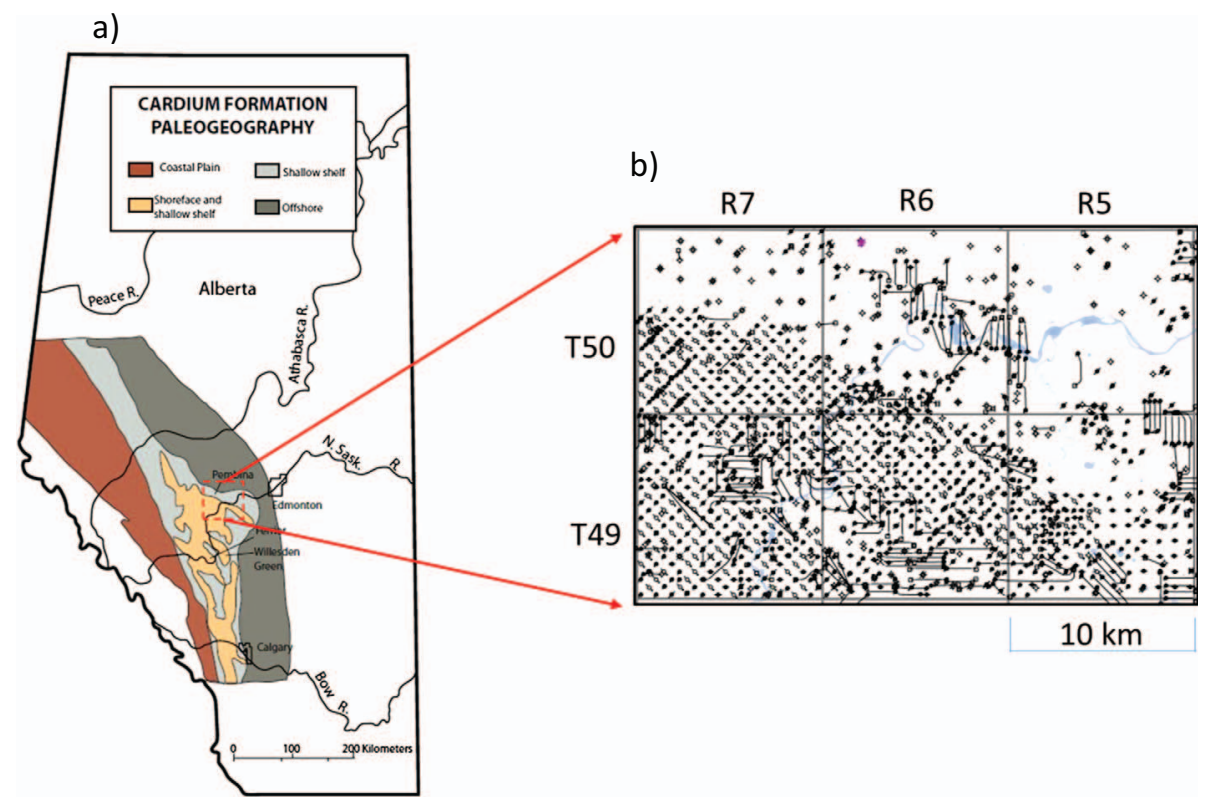

Fig. 6. (a) Alberta map showing Cardium Formation paleogeography (modified from Krause et al., 1994 as cited in Fic, 2013 ); and (b) enlarged map of the East Pembina Oil Field well locations. Vertical wells generally predominate but horizontal wells increase in the northeast.

When it comes to preferential flow paths in the Cardium, in addition to the conglomerate, natural fractures also play an important role. Determining fluid production trends has been a significant challenge in the Cardium Pool. Many authors (e.g., Gough and Bell, 1981; Hassan, 1982; Krause et al., 1987; McLeod, 1987) have studied this topic. It was the prevailing opinion that either a capping conglomerate layer or fractures controlled these trends. Nevertheless, it was not clear which one of these factors was affecting production on a well basis. Using borehole breakouts, Gough et al. (1983) determined that the NE-SW orientation of the maximum stress, $S_{\mathrm{Hmax}}$, extends throughout the Western Canadian Sedimentary Basin (WCSB), northeast of the Rocky Mountains of Alberta and British Columbia. Additionally, Krause et al. (1987) determined that fractures control the NE-SW-oriented water breakthroughs occurring over short periods in the Cardium.

As we will demonstrate with the help of IWC analysis and maps, we can determine the dominant fluid production trends in a particular area from the East Pembina Field and assess lateral continuity, which can help us to exploit an area of interest and compare with the geological characterization. Connectivity assessments can help to identify the major geological controlling factors and provide a guide to well spacing for infill drilling campaigns. IWC can also help to understand how connectivity changes when wells are stimulated.

\subsection{East Pembina Field description and geology}

Our study area is the East Pembina Oil Field (Fig. 6), where the average permeability is less than $1 \mathrm{mD}$. The field was initially drilled on 80- and 160-acre well spacings for wells in the Range 7 - Township 50 and Ranges 6-5 - Township 49 areas, respectively. Most of the wells in the field (Fig. 6b) were vertical wells. More recently, horizontal wells

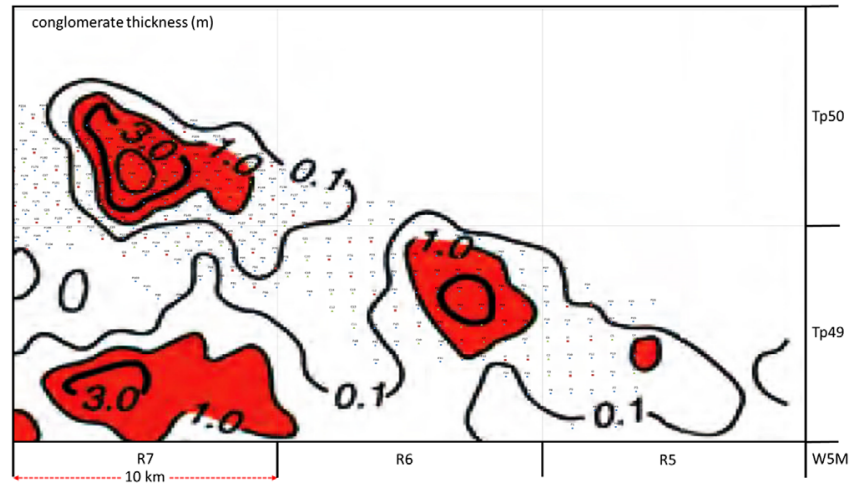

Fig. 7. Conglomerate thickness map of the East Pembina Oil Field (edited from Krause et al., 1994). Conglomerate thickness varies from 0.1 to $9 \mathrm{~m}$ in this area. Contours are in meters: 0.1 , $1.0,3.0$, and 9.0 .

have been added. Most of the vertical wells were fracture stimulated during initial completion. A majority of the wells have been periodically retreated.

Krause et al. (1994) provide a conglomerate isopach where conglomerates are generally orientated NW-SE and the indicated thickness varies from less than $0.1 \mathrm{~m}$ to more than $9 \mathrm{~m}$ in this area (Fig. 7). Krause et al. (1987) report that the conglomerate-bearing zone has thickness ranging from one pebble to $12 \mathrm{~m}$. They observed that conglomerates thinner than $1 \mathrm{~m}$ are packed with shale or siderite matrix and do not have a large influence on fluid flow.

\subsection{IWC evaluation in selected window areas}

We use the CM-PW to evaluate IWC in two areas from the East Pembina Field (Fig. 8). The field was under primary 


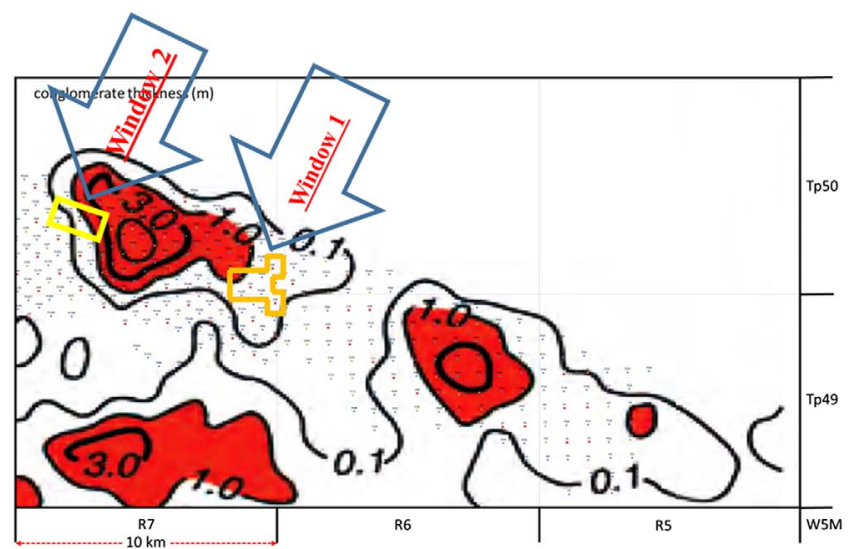

Window 1

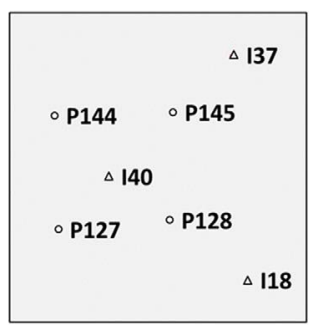

Window 2

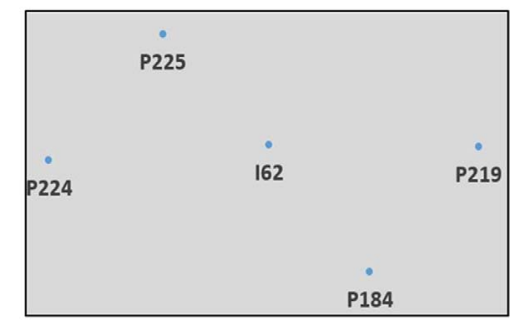

Fig. 8. The East Pembina Oil Field - conglomerate thickness map (edited from Krause et al., 1994). Contours are in meters: $0.1,1.0,3.0$, and 9.0. Orange and yellow colored outlines are the chosen window areas.

depletion until 1967, when waterflooding began. Table 3 summarizes some of the important reservoir and fluid properties. Two areas (Windows 1 and 2) were chosen to study the effects of geology and well treatments on IWC.

For the connectivity evaluation presented below, we use a normalized connectivity measure, $\lambda^{\prime}$, instead of $\lambda$. The normalized connectivity $\lambda^{\prime}, \lambda^{\prime}=\lambda_{\text {hetero }}-\lambda_{\text {homo }}$, where $\lambda_{\text {homo }}$ is the connectivity if the reservoir were homogeneous and $\lambda_{\text {hetero }}$ is the connectivity for the actual reservoir. The use of $\lambda^{\prime}$ instead of $\lambda$ reduces the effects of well distance and reservoir boundaries from the connectivity, as both $\lambda_{\text {hetero }}$ and $\lambda_{\text {homo }}$ contain these effects (Kaviani and Jensen, 2010; Soroush et al., 2014). $\lambda_{\text {homo }}$ is calculated analytically using the Multiwell Productivity Index method (Kaviani and Jensen, 2010). Hence, interpreting $\lambda^{\prime}$ is easier than using $\lambda$ for the evaluation of reservoir heterogeneity because 1) it facilitates connectivity comparisons for wells with differing injector-producer spacing, and 2) it provides a measure of connectivity relative to that obtained in a homogeneous reservoir. Positive $\lambda^{\prime}$ values represent flow conduits (more connectivity than a homogeneous reservoir) while negative $\lambda^{\prime}$ suggests flow barriers (less connectivity than a homogeneous reservoir).

\subsubsection{Window 1 CM-PW analysis}

This area is chosen from a location where the conglomerate is thinner than $1 \mathrm{~m}$, suggesting according to Krause et al.
Table 3. Some important East Pembina Field reservoir and fluid properties (Clarkson and Pedersen, 2011).

\begin{tabular}{lc}
\hline Reservoir rock & Cardium sst and conglomerate \\
\hline Age & U. Cretaceous \\
Net pay (avg.) & $19.3 \mathrm{ft}$ \\
Porosity (avg.) & $13.9 \%$ \\
Permeability (avg.) & $0.7 \mathrm{md}$ \\
Gravity & $37^{\circ} \mathrm{API}$ \\
Initial oil viscosity & $1.4 \mathrm{cp}$ \\
Initial oil FVF & $1.19 \mathrm{RB} / \mathrm{STB}$ \\
Initial reservoir pressure & $\sim 1900 \mathrm{psi}$ \\
\hline
\end{tabular}

(1987) that the conglomerate is not hydraulically important. We chose an area including surrounding producers and two injectors $\mathrm{I} 18$ and I37, and the CM-PW was applied for three periods (Fig. 9). The $R^{2}$ values (CM-PW-predicted $v s$. measured production) of all three periods are fair to good (Tab. 4). For each period, we estimated $L$, the ratio of the number of samples to the number of model parameters. $L$ is a figure of merit for the model, where larger values are better than smaller values. Due to a limited number of measurements for the number of parameters to be evaluated ( $L=4.5)$, the statistical variability of the $\lambda$ s might be a reason for the moderate $R^{2}$ values (Kaviani et al., 2014). Although the 2 nd period $L=3.1$ is smaller than the 1 st period $L$, we obtain a better $R^{2}$. History match plots of all periods are provided in Appendix B.

Prior to the 1st period, all four producers were fractured (Fig. 9). The CM-PW analysis (Fig. 10) reveals that the largest connectivities are oriented in the NE-SW direction, which is consistent with the $S_{\mathrm{Hmax}}$ direction in the WCSB (Bell et al., 1994). The pseudo well connectivity is also directed in the NE-SW direction and contributes only to P127 (Fig. 11). According to Alberta Energy Regulator (2014) reports, the operator fractured P127 with 37.5 tons of 20/40 sand, which is the largest amount of pumped proppant when compared to the other wells in Window 1.

It appears that fracture stimulation of the high permeability well P128 (core $k_{\text {avg }}=190 \mathrm{md}$ ) was not productive; it was abandoned (Fig. 9) with a water cut of $95 \%$ after 6 years of waterflooding. Before the 2 nd period, P145 was fractured again, although the reasons are unclear because the CM-PW analysis suggests this well was adequately supported by both I37 and I40. After the P145 re-stimulation, the connectivity with I37 and I40 decreased and P127 is the only well having $\lambda^{\prime}>0$ (Fig. 12). The connectivity of I40 - P127 may be larger because P127 was fractured initially with 37.5 tons of proppant, which is 12.5 tons more than the amount used to treat P145 during the same period. We cannot further analyze the connectivity change of P144, as we have no information about the fracturing job of that well.

The 2nd period analysis, after P128's abandonment and P145's re-stimulation, shows that P145 benefits very little from the nearby injectors. P145 was fractured for the third 


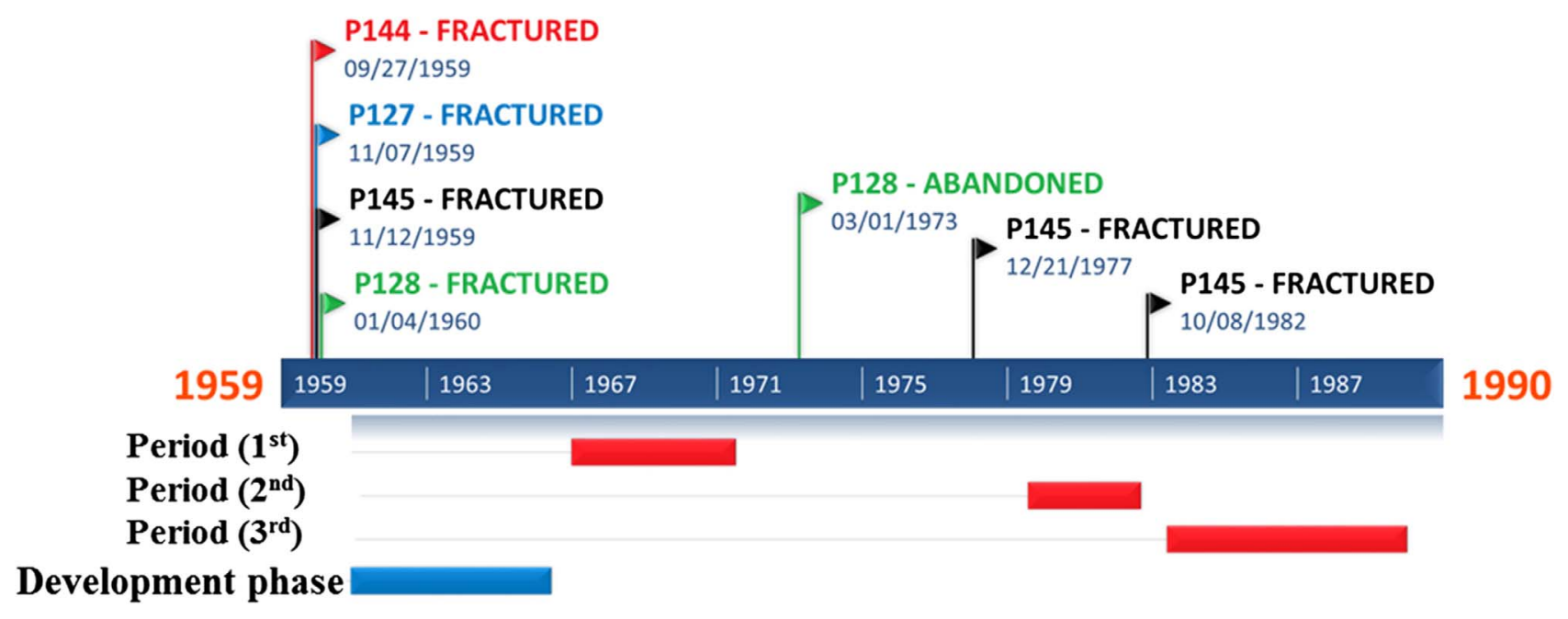

Fig. 9. Timeline of Window 1.

Table 4. Window 1 periods $-R^{2}$ values based on total predicted $v s$. total measured production rates during each period.

\begin{tabular}{lcccc}
\hline Period & $\begin{array}{c}\text { Start date } \\
(\mathrm{dd} / \mathrm{mm} / \text { yyyy })\end{array}$ & $\begin{array}{c}\text { End date } \\
(\mathrm{dd} / \mathrm{mm} / \text { yyyy })\end{array}$ & $R^{2}$ & $L$ \\
\hline 1st & $01 / 01 / 1967$ & $01 / 07 / 1971$ & 0.76 & 4.5 \\
2nd & $01 / 08 / 1979$ & $01 / 09 / 1982$ & 0.83 & 3.1 \\
3rd & $01 / 06 / 1983$ & $01 / 01 / 1990$ & 0.91 & 6.6 \\
\hline
\end{tabular}

time prior to the 3rd CM-PW analysis period (Fig. 9). Further re-fracturing of P145 does not appear to have been effective (Fig. 13); I40 decreased connectivity with all the surrounding producers.

The slope of a cumulative injection vs. time plot (Fig. 14) shows the I40 injectivity changes across the three periods and suggests that injection-induced fractures may have been important (Fig. 10). Period 1 shows the steepest slope in Figure 14, indicating the largest injectivity and exhibits the largest connectivities oriented in the $S_{\mathrm{Hmax}}$ direction. The Period 1 slope is approximately $500 \mathrm{bbl} /$ day, which is much larger than the constrained injection rates typical of this field. Hence, injecting water at this rate creates pressures exceeding the formation breakdown unless there is a significant fracture already present. When the slope of the plot decreases in the 2nd period, we observe that the connection with P145 was lost. However, I40 established a strong connection with P127, which was initially fractured with a larger amount of proppant compared to P145. The increased slope in the 3rd period appears to occur in the fracture shear failure time. Therefore, I40 lost all connections with the surrounding wells. During all three periods, P127 is the only well having strong support from areas outside of the window.

\subsubsection{Window 2 CM-PW analysis}

In this window area (Fig. 15), there are four producers and one injector. We selected three periods (Fig. 16) to study the effects of well treatments and the presence of substantial amounts of conglomerate on IWC. We obtain a very good match between the CM-PW predicted and measured rates for all three periods with $L \geq 3.4$ (Tab. 5). We also observe that $R^{2}$ increases with increasing $L$, which is consistent with Kaviani et al. (2014) findings. History match plots of all periods are provided in Appendix B.

The CM-PW analysis of the 1st period shows that the normalized connectivities between well pairs I62-P224 and I62-P219 are large (Fig. 17).

Since the pseudo well connectivity (Fig. 17) is directed towards the conglomerate-bearing zone in the east, we infer that the conglomerate contributes to the connectivities in this window. Core data from the unfractured wells P225 and P184 also suggest the presence of conglomerate in the east, since the flow capacity (permeability-thickness product, $k h$ ) of P184 is $2 \frac{1}{2}$ times that of well P225 and there appears to be a clear relation between $\lambda^{\prime}$ and $k h$ for these wells (Fig. 18).

P225 is the only well having $\lambda^{\prime}<0$ and the operator may have recognized that this well was receiving little support from I62 because P225 was acid squeezed twice and fractured with 8.5 tons of $10 / 20$ sand after the 1 st period (AER (2014) reports). CM-PW analysis in the 2 nd period (Fig. 19) indicates the connectivity of P225 increased by 0.16 (i.e., $\Delta \lambda^{\prime}=\lambda_{\text {period } 2}^{\prime}-\lambda_{\text {period } 1}^{\prime}=0.16$ ), and the connectivity of I62 with other producers either decreased (I62 - P184) or remained the same (I62 - P224). The pseudo well still exhibits the strongest support directed to the east (Fig. 20).

A plot of $\Delta \lambda^{\prime} v s$. proppant tonnage for the treatments of wells P225 and P184 shows a direct proportion (Fig. 21), where we have added the point at the origin on the basis that zero proppant should leave the connectivity unchanged. 


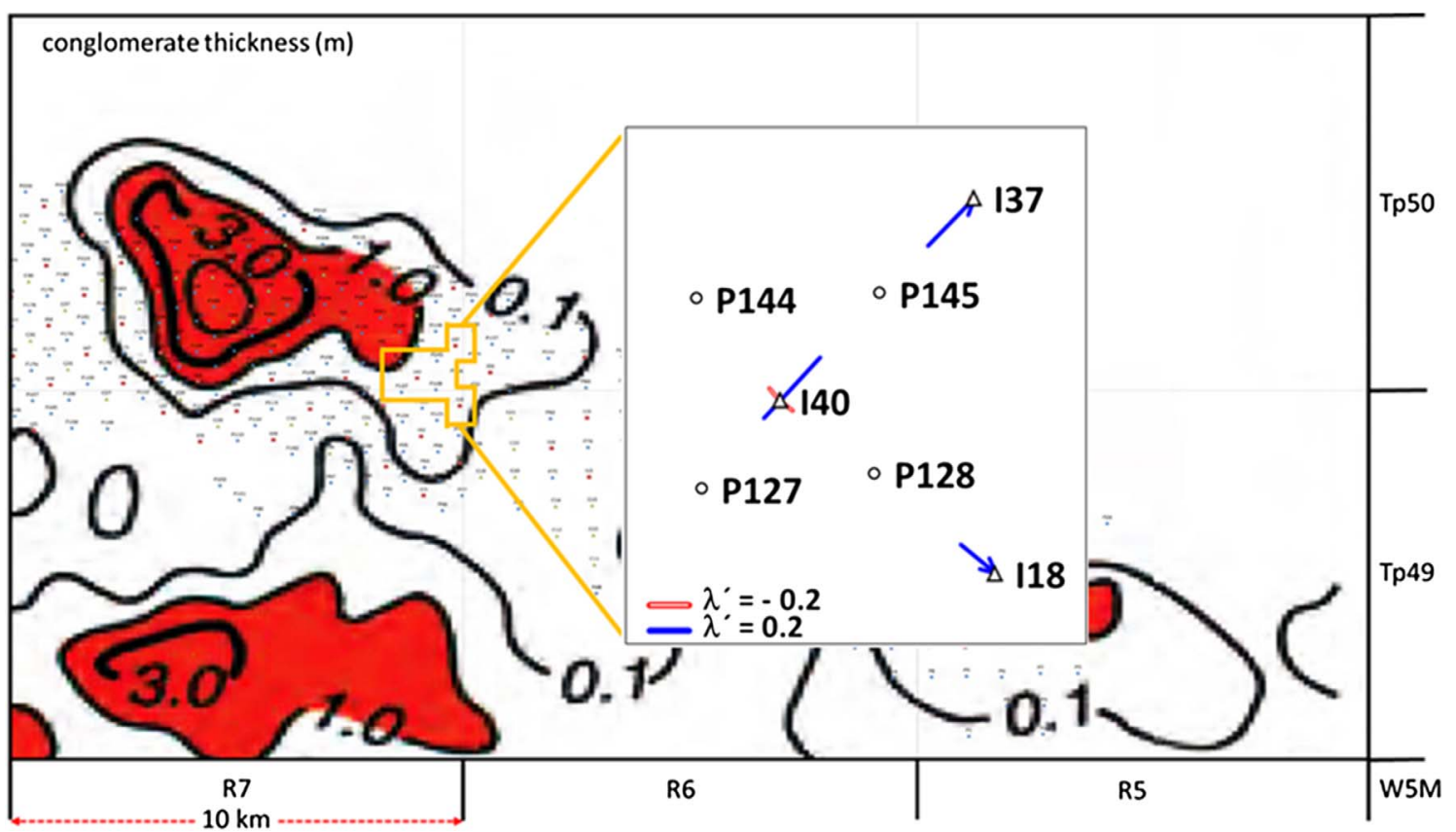

Fig. 10. Window 1 - normalized connectivity map of the 1st period. Connectivities are larger in the NE-SW direction, consistent with the direction of larger horizontal principal regional stress.

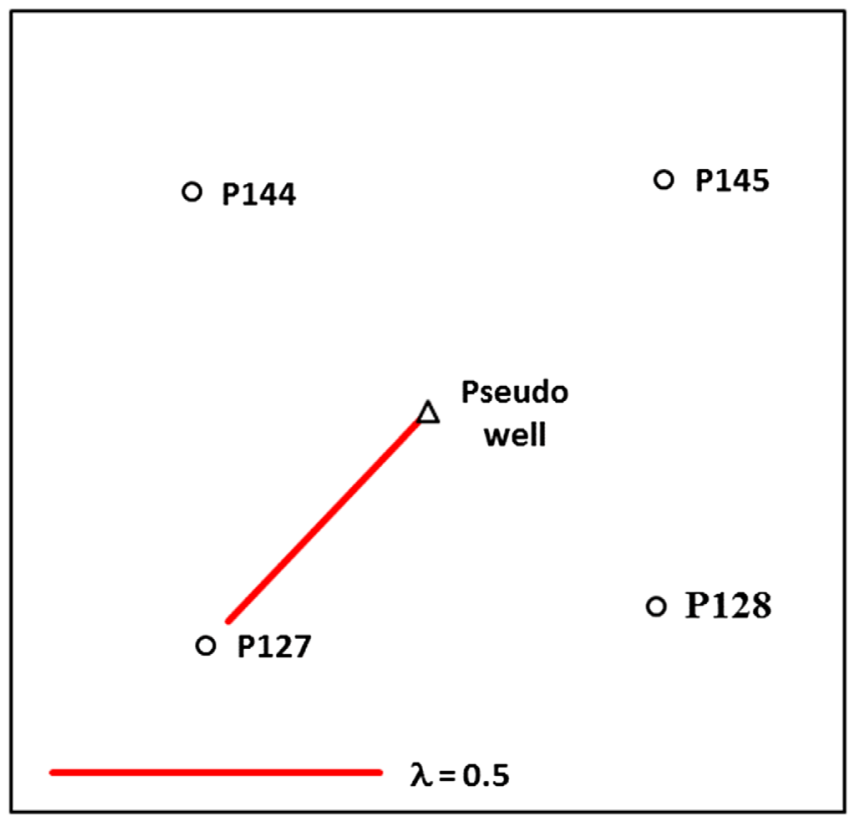

Fig. 11. Pseudo well connectivity during the 1st period, showing strong connectivity from wells outside the area with well P127.

After all the treatments, the I62 - P184 connectivity was strong during the 3rd period (Fig. 22). The pseudo well also shows a strong connection with P225 and P184 (Fig. 23). P225 connectivity has improved after the suspension of some wells outside the areal window. It may be

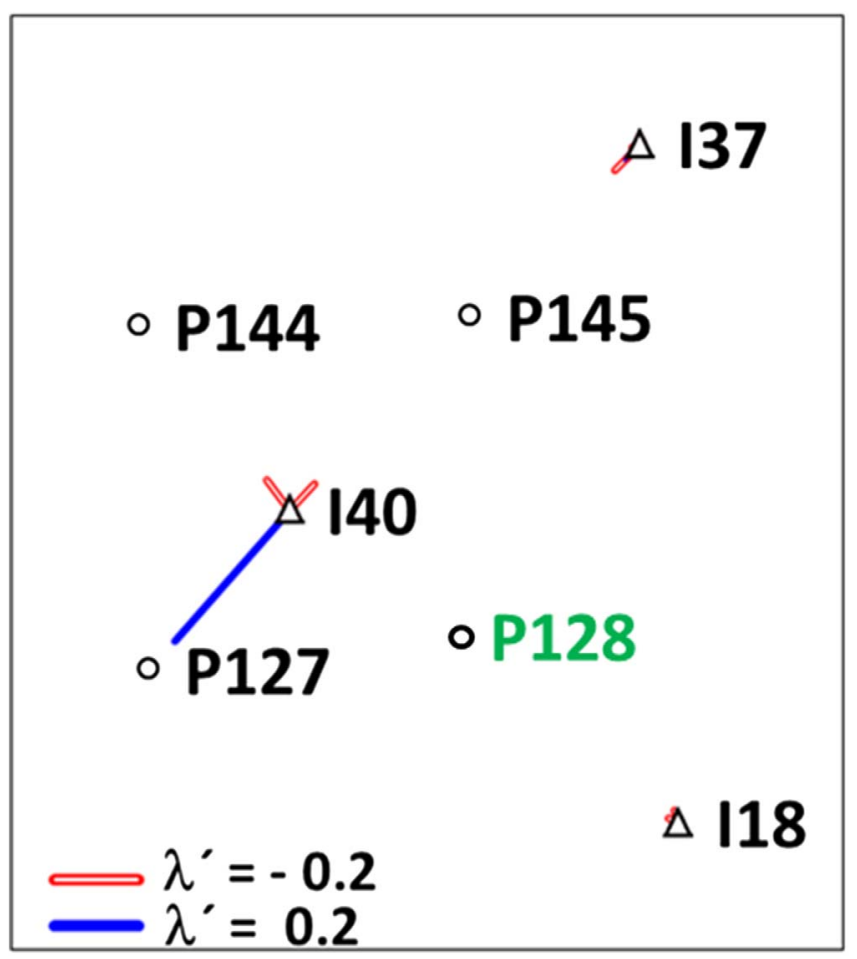

Fig. 12. Window 1 - normalized connectivity map of the 2 nd period (P128 abandoned, P145 refractured in 1977).

that re-fracturing P184 reactivated the connection with both the injector and the conglomerate-bearing region. Fracturing the wells close to the thick conglomerate zone 


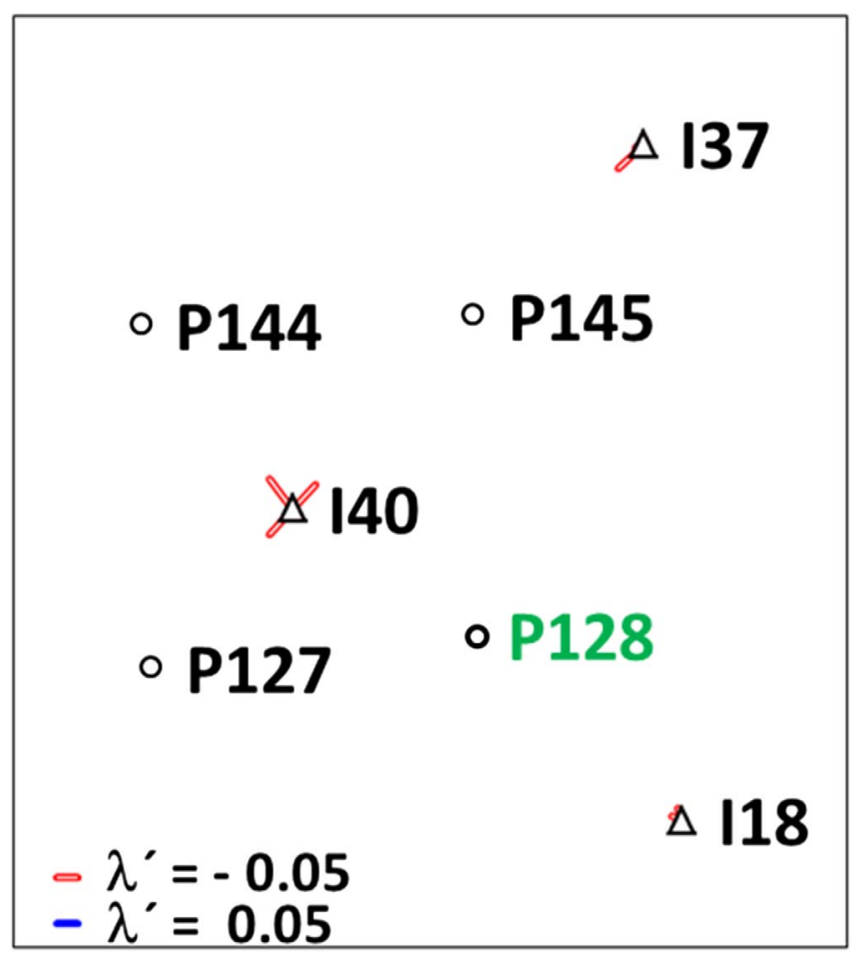

Fig. 13. Window 1 - normalized connectivity map of the 3rd period (P145 fractured, P128 abandoned).

might increase the connection with that zone; therefore, fracturing those wells close to the conglomerate region could be considered a successful operation to extract oil from that zone.

\section{Discussion}

Testing the modified model (CM-PW) with simulation model cases with low permeability showed that it can determine heterogeneities and estimate connectivity of a source outside of a window area. For the permeability of $0.1 \mathrm{md}$, connectivities of long distance pairs are often very small except, perhaps, in the case of natural fractures. It would be interesting to test the model in a naturally fractured low permeability case.

In the Cardium Formation, for a few lithofacies, lateral continuity in the East Pembina Oil Field has been studied. Butrenchuk et al. (1995) report that high lateral continuity in sandstones and shales would be likely to occur if the depositional model of a NW-SE prograding shoreline stepping out into the basin were the case. P184's strong connection with I62 in Window 2 suggests that there exists a significant hydraulic continuity between this well pair having an interwell distance of $1916 \mathrm{ft}$. This distance is larger than the Krause et al. (1987) assumption that the lithofacies extend halfway between wells. It appears that the conglomerate is an important element in the connectivity of wells, even where only some of the wells show conglomerate. During the 1st period of the Window 2 analysis, the pseudo well connectivity map showed that there is strong support from the thick conglomerate-bearing region. As for Window 1, we could not infer anything about lateral continuity because the wells were fractured before any of the CM-PW analyses.

The field case applications showed that having a pseudo-well in the model helps to identify the contribution of a high permeability layer (the conglomerate) to the wells in contact with that layer. Similar to Krause et al. (1987), we also determined that an area with a significant conglomerate layer $(>1 \mathrm{~m}$ thick) contributes to IWC and thereby to total production. There are some wells in the eastern parts of the East Pembina Oil Field which are located in the thin conglomerate-bearing regions, and these wells might still benefit because of proximity to the thicker portions. It is possible the hydraulic fractures of these wells might penetrate to the thicker parts of the conglomerate layer. Having microseismic images of these wells would help us to characterize these phenomena.

By analyzing the connectivities after well treatments, insights into the stimulation effects are possible. In Window 1, the CM-PW identified the wells in need of treatment during all the periods. We determined that well connectivity increased with the amount of proppant used. It remains unclear how the field operator identified the wells to treat; we could not locate reports evaluating whether the stimulations were considered successful. We also could not find any study covering how hydraulic fracture networks change shape with time in the Cardium pool. Window 1 seems to be more stress sensitive than the Window 2 since re-fracturing could not improve the P145 connectivity. Well P127, initially fractured with a larger amount of proppant, kept benefiting from injection outside of the chosen area during all the periods. The 1st period results were in agreement with the $S_{\mathrm{Hmax}}$ in the region. We have some questions left unanswered however, as most of these wells lack detailed reports.

The analyses suggest that fracturing all the wells or re-fracturing might not be the best solution to preserve existing connections with surrounding wells. For instance,

1. Fracturing a well located in a high permeability zone might establish a connection with a possible waterbearing zone, which causes a very high watercut in the early period of that well. P128 from the Window 1 was one of those wells.

2. Re-fracturing can reopen a closed fracture, which might re-establish a connection with an injector through an already swept zone and reduce or lose connection with a current contributor.

3. Re-fracturing can starve other producers of injection support, as we saw in Window 1.

As the reservoir is waterflooded, fracture shear failure might occur, and which directly affects the connectivity of a fractured well (Palmer et al., 2007). For example, after the 1st period, P145 did not communicate with the injectors I40 and I37 aligned along the direction of $S_{\mathrm{Hmax}}$. Injection induced fractures can also affect the IWC, which could cause needless remedial work on nearby producers. Therefore, determination of threshold injection rates to avoid 


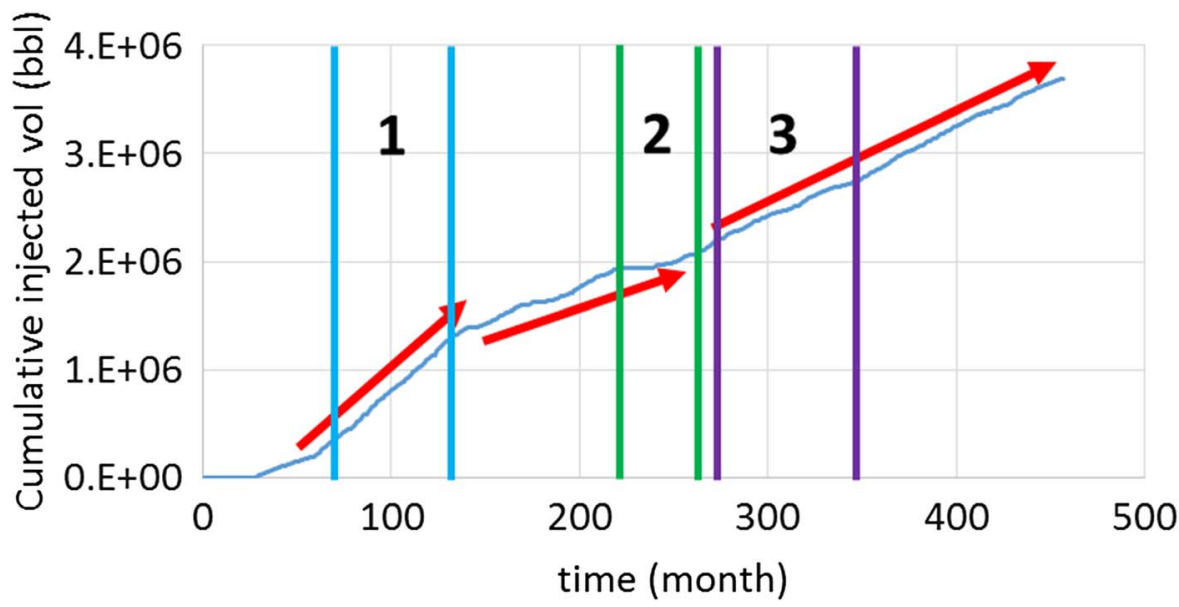

Fig. 14. Cumulative injected volume with respect to time for injection well I40 (the numbers 1,2 and 3 correspond to the periods shown in Fig. 9 and Tab. 4).

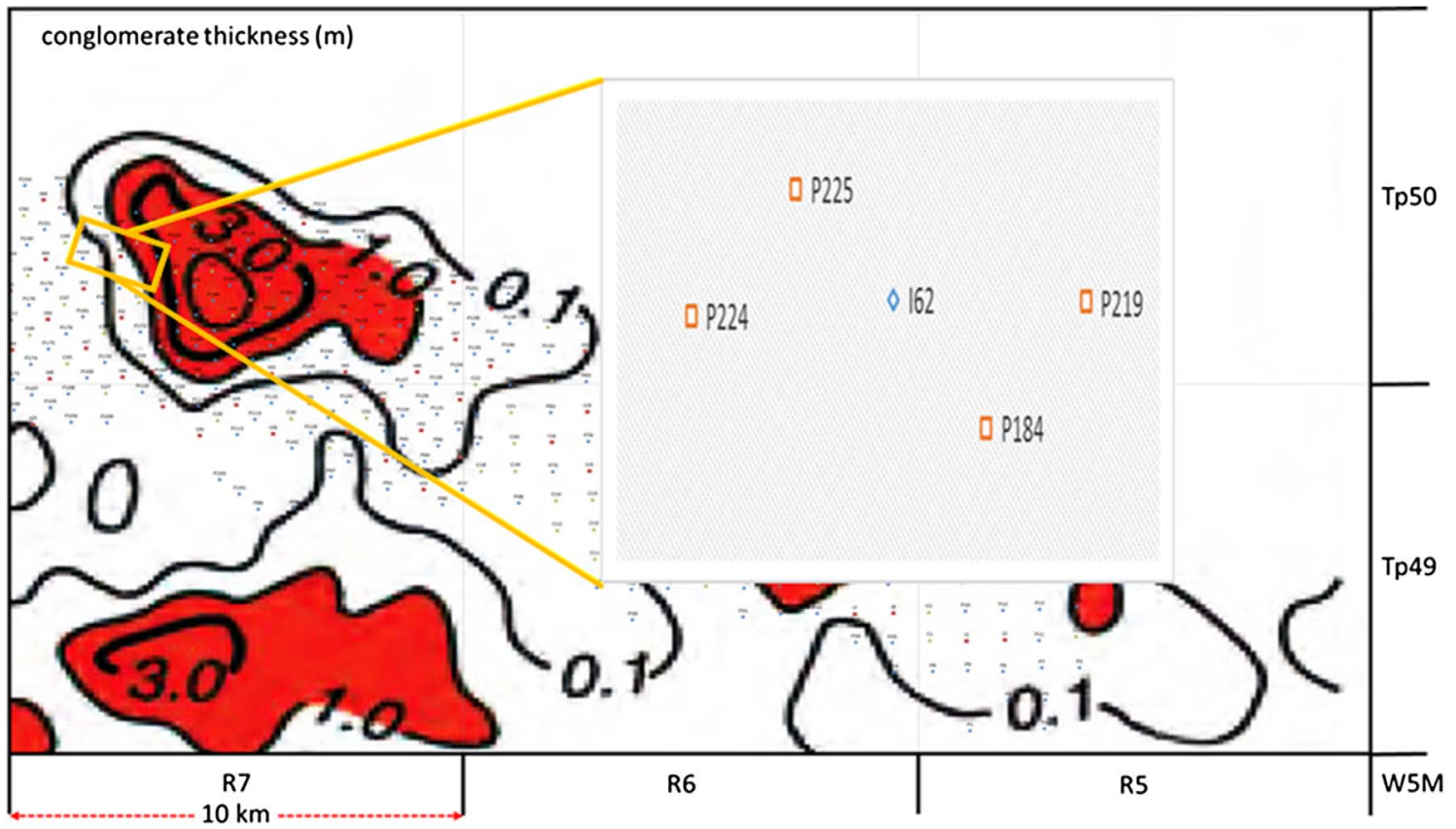

Fig. 15. Window 2 - location and its proximity to significant conglomerate thicknesses.

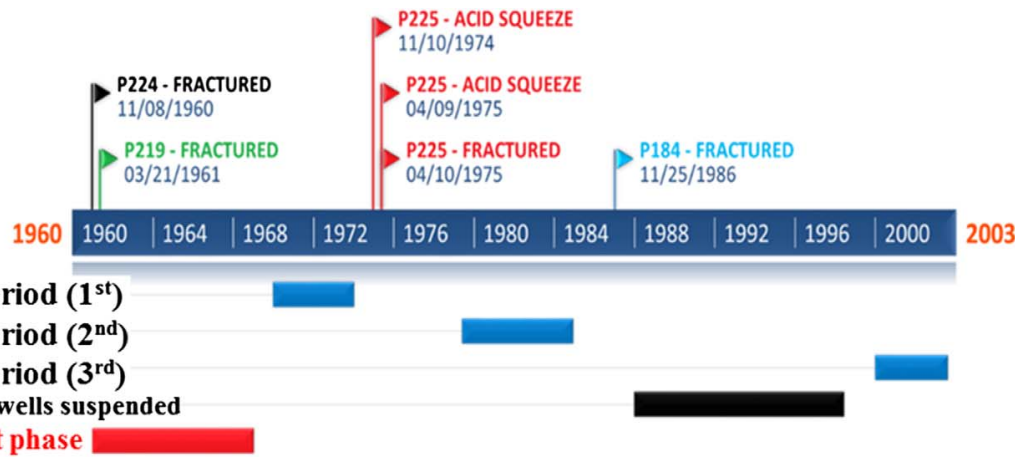

Fig. 16. Window 2 - well treatment timeline (I62 and P 219 were intermittently suspended). 
Table 5. Window $2-R^{2}$ values of total predicted $v s$. total measured production rates during each period.

\begin{tabular}{lcccc}
\hline Period & $\begin{array}{c}\text { Start date } \\
(\mathrm{dd} / \mathrm{mm} / \text { yyyy })\end{array}$ & $\begin{array}{c}\text { End date } \\
(\mathrm{dd} / \mathrm{mm} / \text { yyyy })\end{array}$ & $R^{2}$ & $L$ values \\
\hline 1st & $01 / 07 / 1970$ & $01 / 06 / 1974$ & 0.91 & 4.7 \\
2nd & $01 / 06 / 1979$ & $01 / 12 / 1984$ & 0.95 & 6.6 \\
3rd & $01 / 02 / 2000$ & $01 / 07 / 2003$ & 0.89 & 3.4 \\
\hline
\end{tabular}

$\circ \mathrm{P} 225$

○ P224

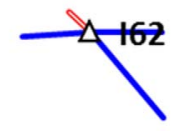

○ P219

$\lambda^{\prime}=-0.25$

$\lambda^{\prime}=0.25$

Fig. 17. Window 2 - 1st period - connectivity map where P224 and P219 are fractured (the plot in the lower right corner shows pseudo well connectivity).

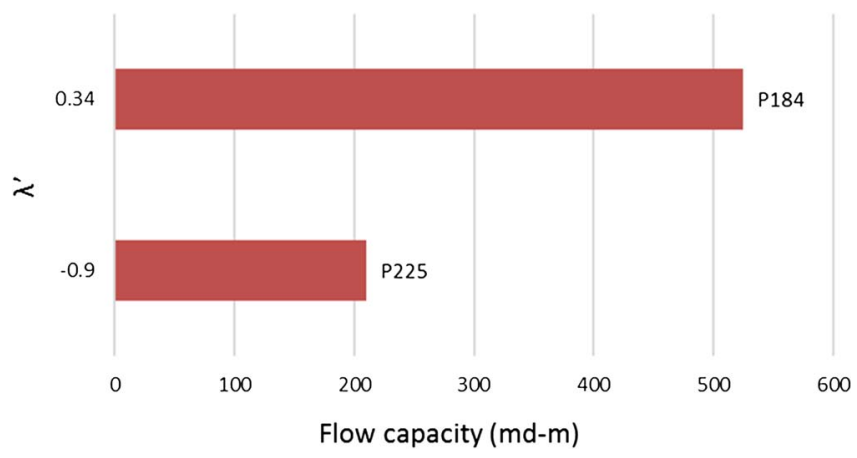

Fig. 18. $\lambda^{\prime}$ vs. $k_{\max } h$ for the initially unfractured wells $\mathrm{P} 184$ and P225; the connectivities are consistent with the well flow capacities.

fracturing a formation might avoid such causes. It seems I40 had injection-created fractures during the 1st period because the cumulative injected volume plot shows the largest slope and I40 had positive normalized connectivity with both P127 and P145 and aligning with the $S_{\mathrm{Hmax}}$.

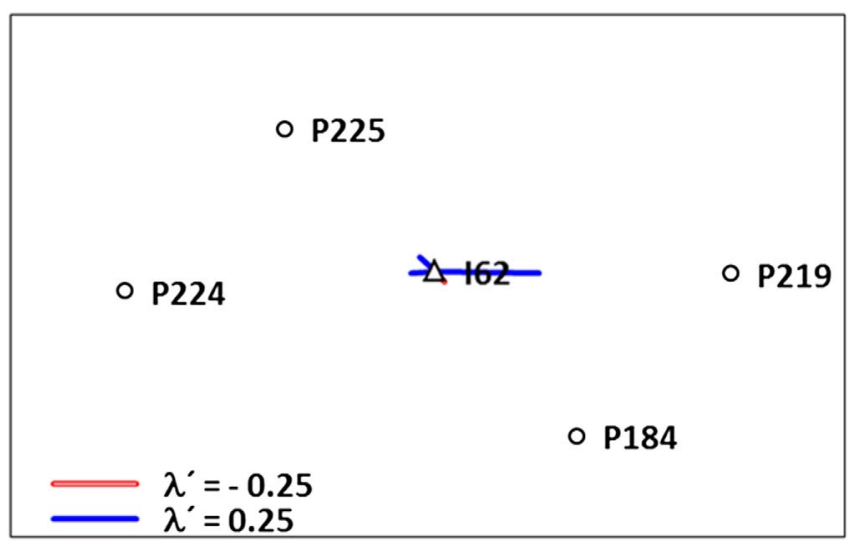

Fig. 19. Window 2 - the connectivity map after acid squeezing and fracturing P225 (2nd period).

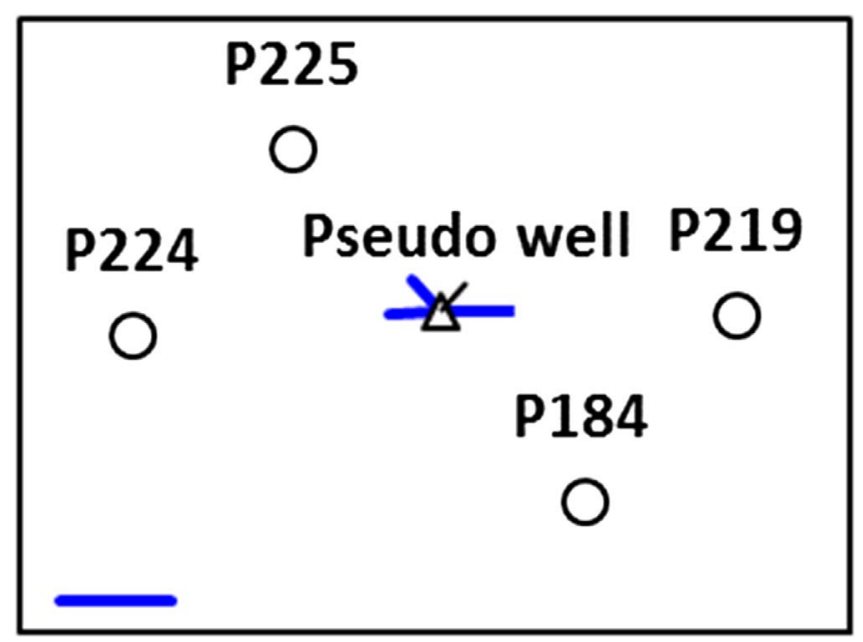

Fig. 20. Pseudo well connectivity during the 2nd period shows largest connectivity with P219 the east.

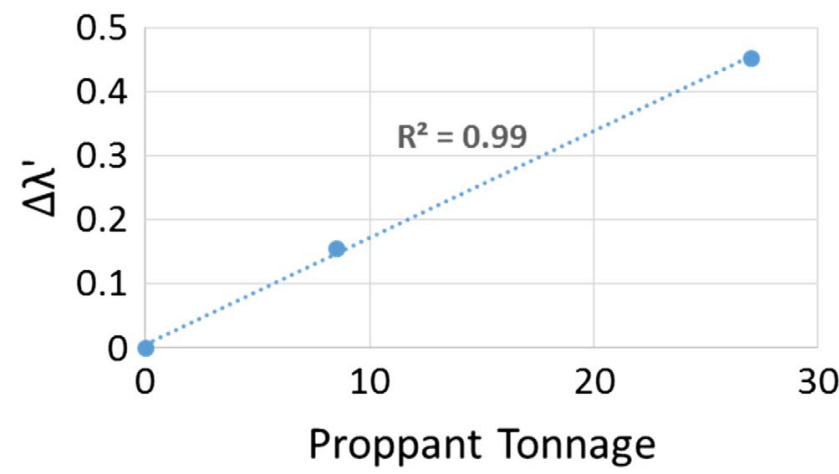

Fig. 21. Change in connectivity, $\Delta \lambda^{\prime}$, vs. proppant tonnage suggests a linear relationship, where the point at the origin is added from physical reasoning. 


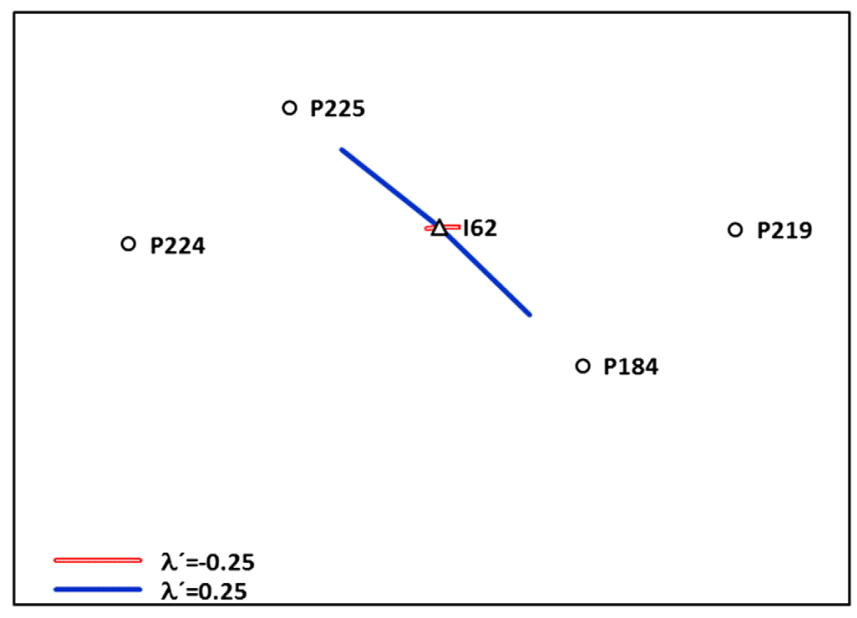

Fig. 22. Window 2 - connectivity map during the 3rd period.

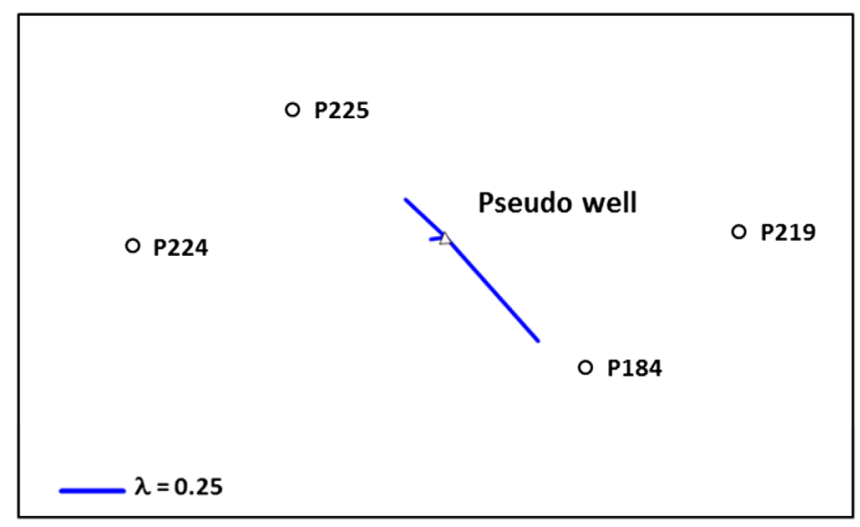

Fig. 23. Pseudo well connectivity during the 3rd period.

\section{Conclusion}

We have tested the CM-PW with homogeneous and vertical wells in low permeability models and observed that it can estimate connectivities in low permeability simulation models. It has successfully identified heterogeneities in the model from Section 2.2.

The analysis of the two study areas using the CM-PW gives promising results and insights:

- Early time IWC of fractured wells was consistent with the regional stress.

- Refracturing does not always offer improvement; it can impair IWC for some situations.

- Injection induced fractures can contribute significantly to the IWC.

- The type of heterogeneity controlling the IWC in a system may depend on the nature of the stimulations and their interactions with depositional heterogeneities. For the Cardium, conglomerates enhanced connectivities with nearby injectors.

- There exists significant hydraulic communication between the well pairs having interwell distances of approximately $2000 \mathrm{ft}$. i.e. 80 -acre well spacing, which is more than the $285 \mathrm{~m}$ value predicted by Krause et al. (1987) and similar to that $(570 \mathrm{~m})$ predicted by Butrenchuk et al. (1995).

The field study results suggest that well treatments need to be carefully designed with the geological heterogeneities in mind in order to avoid unintended reductions of IWC.

Acknowledgments. The authors wish to thank the sponsors of the Tight Oil Consortium (TOC) at the University of Calgary. MM was funded by an NSERC CRD grant (CRDPJ 452752 2013). Jerry L. Jensen holds the Schulich Chair in Geostatistics at the University of Calgary.

\section{References}

Alberta Energy Regulator (2014) AER database: Tour reports East Pembina field wells.

Bell J.S., Price P.R., McLellon P.J. (1994) In-situ stress in the Western Canada Sedimentary Basin, in: Geological Atlas of the Western Canada Sedimentary Basin, Mossop G.D., Shetsen I. (eds), Canadian Society of Petroleum Geologists, Alberta Research Council, pp. 439-446.

Braunberger W.F., Hall R.L. (2001) Ammonoid faunas from the Cardium formation (Turonian-Coniacian, Upper Creataceous) and contiguous units, Alberta, Canada: I. Scaphitidae, Can. J. Earth Sci. 38, 333-346. DOI: 10.1139/cjes-38-3-333.

Butrenchuk E.W., Cornish S.A., Leggit S.M., Mills M.M. (1995) The impact of facies on reservoir performance: Pembina Cardium Reservoir, Alberta, Presented at: $C S P G / C W L S$ 1995 core session: The economic integration of geology and formation evaluation, Canadian Society of Petroleum Geologists, Calgary, Alberta, Canada, pp. 1-32.

Clarkson C.R., Pedersen P.K. (2011) Production analysis of western Canadian unconventional light oil plays, Paper CSUG/SPE 149005. Presented at: the Canadian Unconventional Resources Conference Calgary, 15-17 November.

Fic J.D. (2013) Characterization of the lower Shoreface to offshore reservoir facies of the Cardium formation in East Pembina, Alberta, MSc Thesis, Retrieved from https://prism. ucalgary.ca/handle/11023/444.

Gillund G.N. (1969) Review of the Lobstick Cardium miscible flood, J. Can. Pet. Tech. 8, 66-74.

Gough D.I., Bell J.S. (1981) Stress orientations from oil-well fractures in Alberta and Texas, Can. J. Earth Sci. 18, 638-645.

Gough D.I., Fordjor C.K., Bell J.S. (1983) A stress province boundary and tractions on the North American plate, Nature 305, 619-621, Letters to Nature.

Hassan D. (1982) A method for predicting hydraulic fracture azimuth and the implications thereof to improve hydrocarbon recovery, 33rd Annual Technical Meeting of the Petroleum Society of Canadian institute of Mining and Metallurgy, Calgary, AB, Paper 82-33-19.

Kaviani D., Jensen J.L. (2010) Reliable connectivity evaluation in conventional and heavy oil reservoirs: A case study from Senlac heavy oil pool, western Saskatchewan, Paper SPE-137504. Presented at: the Canadian Unconventional Resources and International Petroleum Conference Calgary, Alberta, 19-21 October. DOI: 10.2118/137504-MS.

Kaviani D., Soroush M., Jensen J.L. (2014) How accurate are capacitance model connectivity estimates? J. Pet. Sci. Eng. 122, 439-452. 
Kloepfer C.V., Griffith J.D. (1965) Solvent placement improvement by pre-injection of water - Lobstick Cardium Unit, Pembina field, J.Can. Pet. Tech. 4, 30-35.

Krause F.F., Collins H.N., Nelson D.A., Machemer S.D., French P.R. (1987) Multiscale anatomy of a reservoir: geological characterization of Pembina-Cardium pool, West-Central Alberta, Canada, Am. Assoc. Pet. Geol. Bull. 71, 10, 1233-1260.

Krause F.F., Deutsch K.B., Joiner S.D., Barlcay J.E., Hall R.L., Hills L.V. (1994) Cretaceous Cardium formation of the western Canada sedimentary basin, Geological Atlas of the Western Canada Sedimentary Basin. pp. 375-385. Retrieved September 12, 2017, from http://ags.aer.ca/publications/ chapter-23-cretaceous-cardium-formation.htm.

Liang X., Weber D., Lake L.W., Edgar T.F., Sayarpour M., Al-Yousef A. (2007) Optimization of oil production based on a capacitance model of production and injection rates. SPE-107713-MS, DOI: 10.2118/107713-MS.

McLeod J.G.F. (1987) Successful injection pattern alternation, Pembina J lease, J. Can. Pet. Tech. 17, 51-55.

Mirzayev M., Riazi N., Cronkwright D., Jensen J.L., Pedersen P.K. (2017) Determining well-to-well connectivity using a modified capacitance model, seismic, and geology for a Bakken Waterflood, J. Pet. Sci. Eng. 152, 611-627.

Noetinger B. (2016) About the determination of quasi steady state storativity and connectivity matrix of wells in $3 \mathrm{D}$ heterogeneous formations, Math. Geosci. 48, 6, 641-662.

Palmer I.D., Moschovidis Z.A., Cameron J.R. (2007) Modeling shear failure and stimulation of the Barnett shale after hydraulic fracturing, SPE-106113-MS. Presented at: the SPE Hydraulic Fracturing Technology Conference, College Station, Texas, 29-31 January. DOI: 10.2118/106113MS.

Soroush M., Kaviani D., Jensen J.L. (2014) Interwell connectivity evaluation in cases of changing skin and frequent production interruptions, J. Pet. Sci. Eng. 122, 616-630.

Weber K.J., van Geuns L.C. (1990) Framework for constructing clastic reservoir simulation models, J. Pet. Tech. 42, 10, 1248-1297.

Yousef A.A., Gentil P.H., Jensen J.L., Lake L.W. (2006) A capacitance model to infer interwell connectivity from production and injection rate fluctuations, SPE Res. Eval. Eng. 9, 6, 630-646. DOI: 10.2118/95322-PA. 


\section{Appendix A}

\section{Testing CM-PW with homogeneous low permeability case}

We test the model with the simulated production rates from a $5 \times 4$ nearly-homogeneous low permeability model with constant BHPs (Tab. A1, Fig. A1). The simulation runs for 299 months and the data are sampled every 3 months (Fig. A2). Injection rates are produced using the East Pembina Field wells' hydraulic fracturing pressure as a constraint. Therefore, they should be in the range of injection rates shown in Figure A2, as we attempt to preserve formation without fracking it. When we apply the CM-PW to evaluate IWC for this case, we deliberately exclude I05, so we create an imbalance in the system before running the model.

The estimated connectivities of I05 in the low permeability model are similar to the corresponding connectivities from the other corner injectors (Fig. A3, within 14\%). The model accuracy (i.e., total simulated vs. total CM-predicted production rates) is very high $\left(R^{2} \geq 0.99\right.$, Fig. A4). When compared to the conventional (40 md of Yousef et al., 2006) case results, the points lie along the 1:1 line with slightly larger variation (Fig. A5). Compared to the conventional case, the support from the long-distance injectors in low permeability formations decreases by $\sim 50 \%$, while direct connectivities increase by $\sim 18 \%$. For example, the effect of a $1 \mathrm{bbl} /$ day change at I01 on P03 is only $33 \%$ of the effect of the same change at I02 on P03. Because of the relatively large interwell distance and strong attenuation effect by the porous medium, the effect of the long-distance support from each injector is masked by

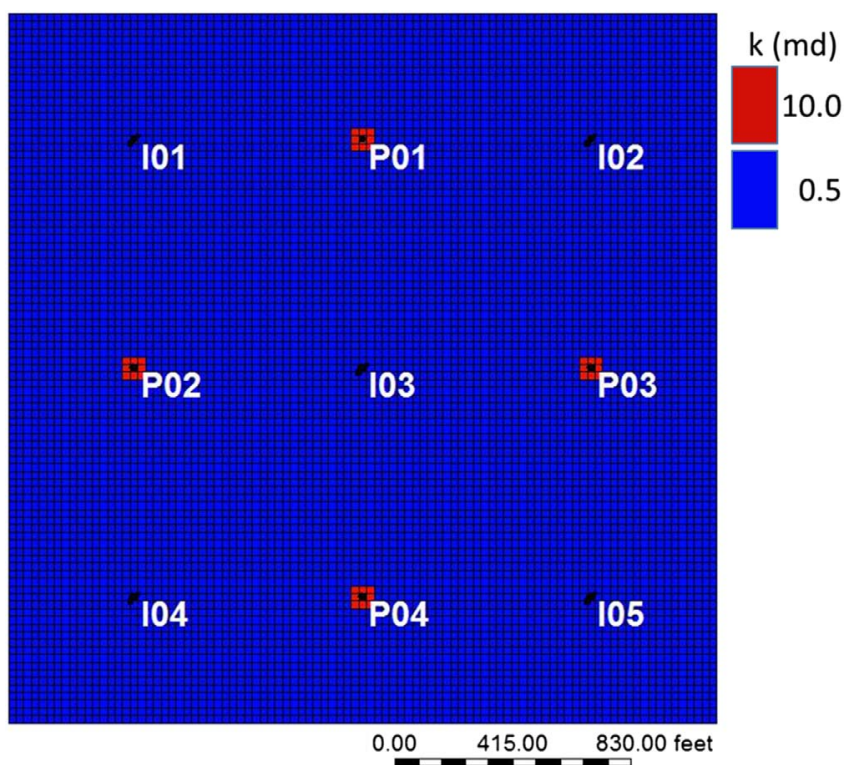

Fig. A1. $5 \times 4$ semi-homogeneous model with producers stimulated (-2 skin) by an enhanced near well region (10 md); production and injection wells are denoted by $\mathrm{P}$ and $\mathrm{I}$, respectively.

the near-well influence, which increases the variability of the $\lambda$ estimates.

In the case when I05 is not included in the model, the history match (the simulated $v s$. predicted production rates) using the CMP is mediocre (Fig. A6-a). On the other hand, we get a good match employing the CM-PW (Fig. A6-b).

Table A1. Reservoir and fluid data used for the semi-homogeneous $5 \times 4$ model.

\begin{tabular}{|c|c|c|c|}
\hline Parameter & Value & Parameter & Value \\
\hline Porosity, $\varphi$, fraction & 0.18 & Fluid viscosity, $\mu, c p$ & 0.5 \\
\hline Horizontal $k_{\text {matrix }}$, md & 0.5 & Reservoir size in $x$-direction, $\mathrm{ft}$ & 2480 \\
\hline Vertical $k_{\text {matrix }}$, md & 0.05 & Reservoir size in $y$-direction, $\mathrm{ft}$ & 2480 \\
\hline Producer $k_{\text {near wellbore }}, \mathrm{md}$ & 10 & Formation thickness, ft & 27 \\
\hline Total compressibility, $c_{\mathrm{t}}, \mathrm{psi}^{-1}$ & $2 \times 10^{-6}$ & Reservoir depth, $\mathrm{ft}$ & 3000 \\
\hline Reservoir pressure, psi & 1470 & Model dimensions & $93 \times 93 \times 1$ \\
\hline$\mu_{\mathrm{oil}}, c p$ & 2 & $\mu_{\text {water }}, c p$ & 0.5 \\
\hline
\end{tabular}

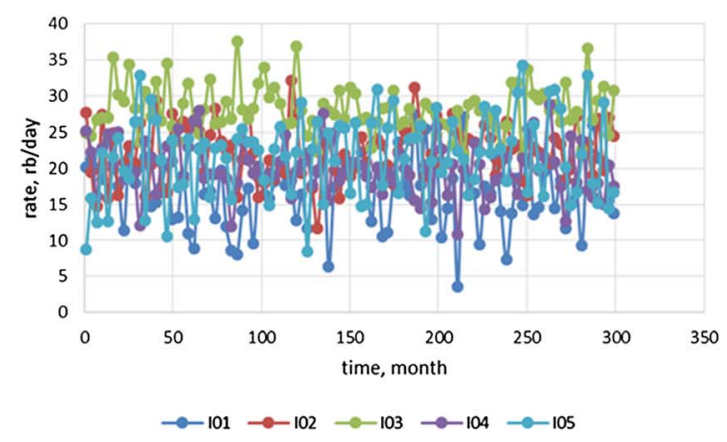

a. Injection rates

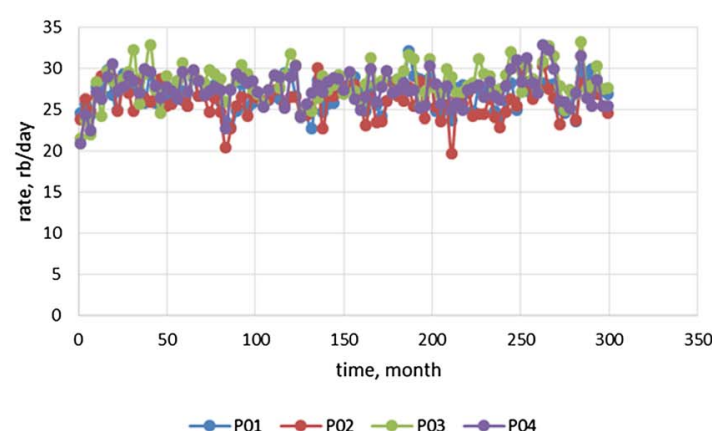

b. Production rates

Fig. A2. Case 3-1 injection and production rates (sampled every 3 months). 

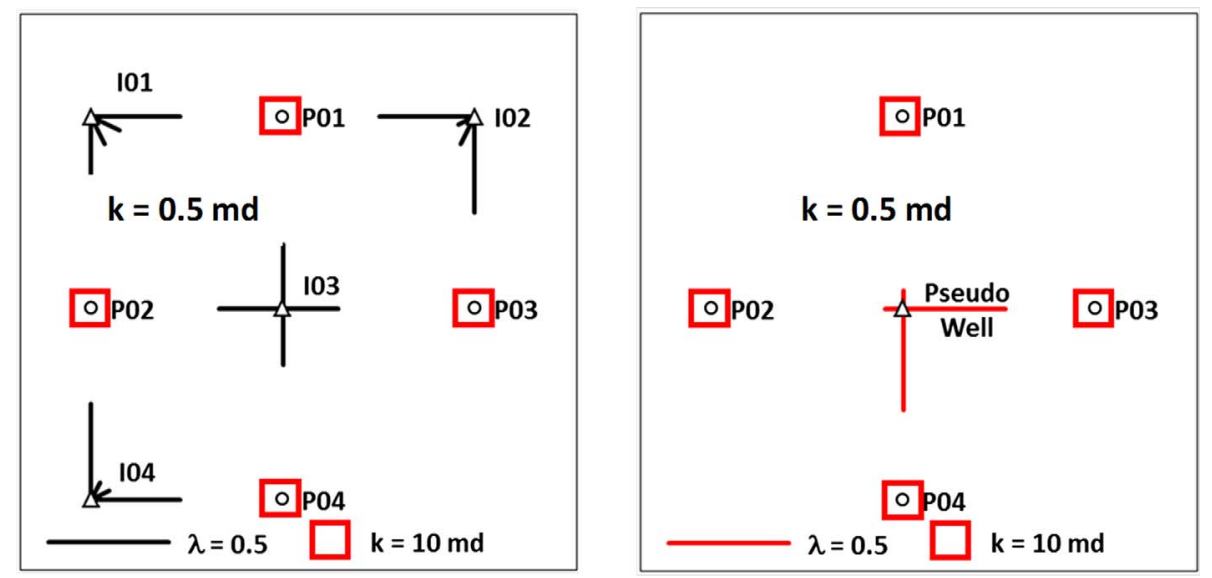

Fig. A3. Left figure: CMP-PW values ( $\lambda$, shown with a line indicating the direction and the magnitude of connectivity) from the model with the pseudo well (I05). Right figure: The pseudo well is placed in the center of the map where only producers are shown.

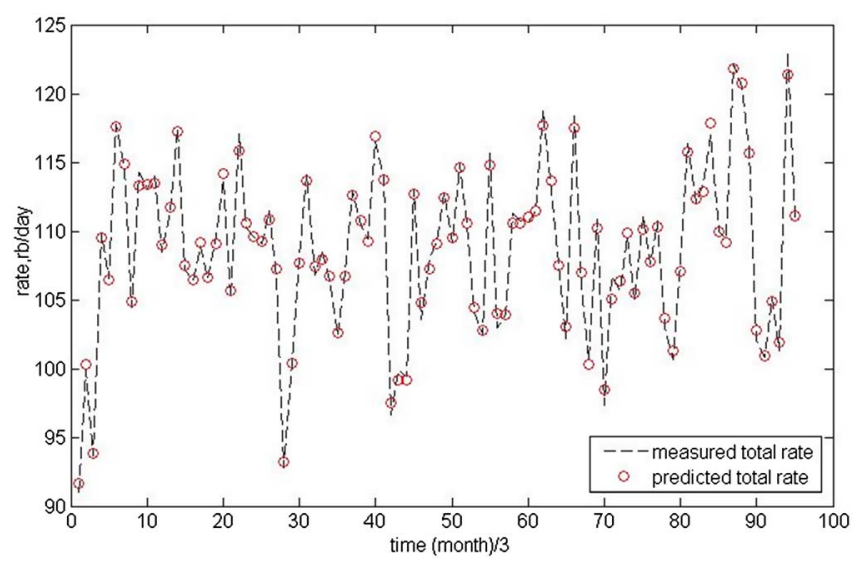

Fig. A4. Case 3-1 CM-predicted total rate vs. simulator-based total rate $\left(R^{2} \geq 0.99\right)$ - Pseudo well: I05.

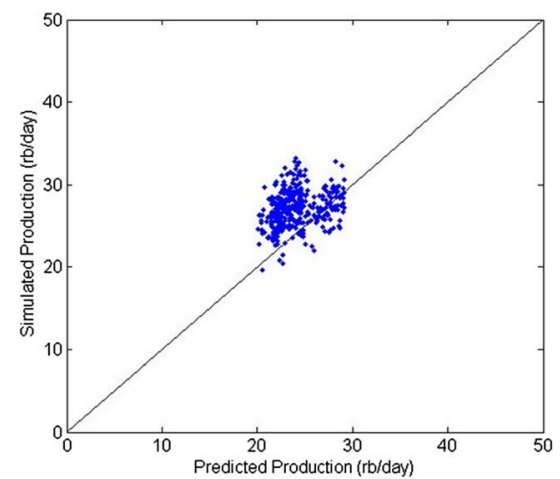

a. CMP

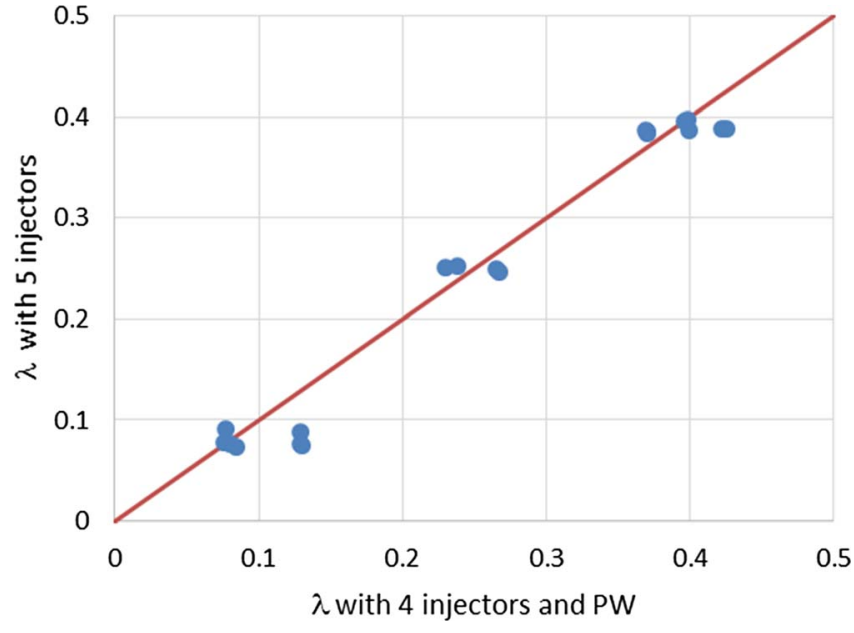

Fig. A5. Connectivities from the case with I05 excluded vs. connectivities from the case I05 included.

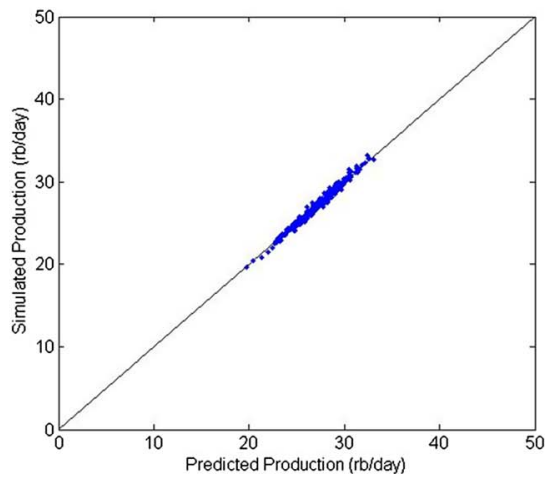

b. CMP-PW

Fig. A6. I05 not included history match plots from CMP (left) \& CMP-PW (right). 


\section{Appendix B}

\section{History match plots}

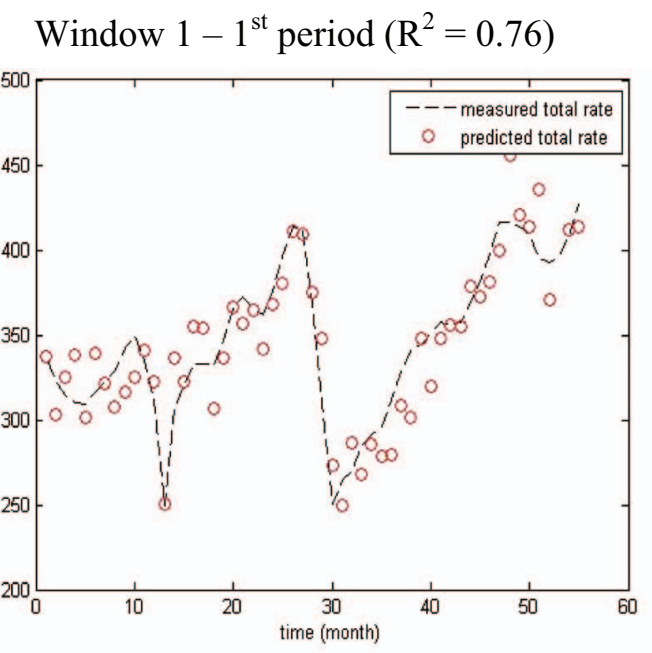

Window $1-2^{\text {nd }}$ period $\left(\mathrm{R}^{2}=0.83\right)$

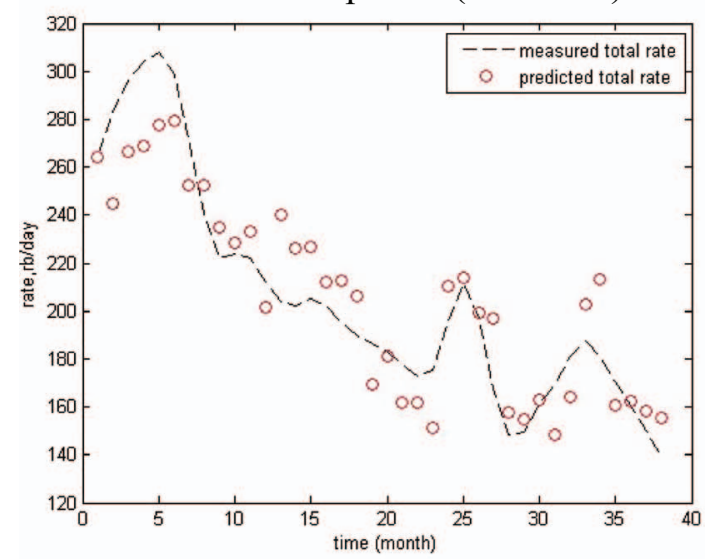

Window $1-3^{\text {rd }}$ period $\left(\mathrm{R}^{2}=0.91\right)$

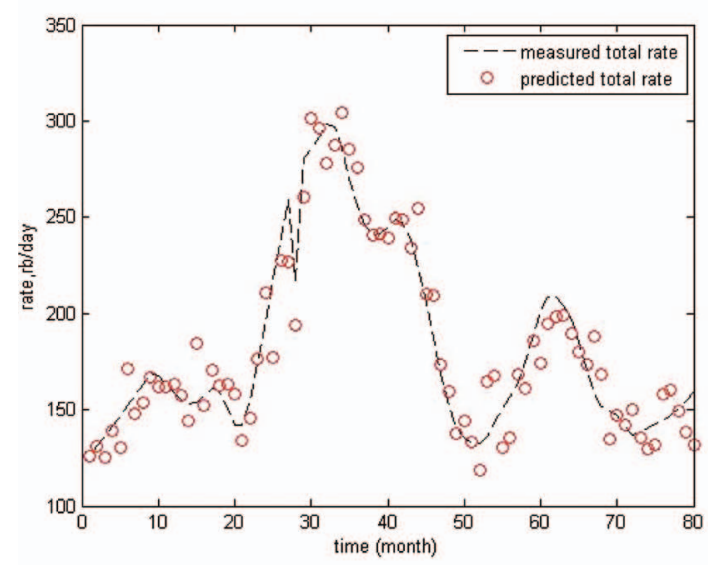

Window $2-1^{\text {st }}$ period $\left(\mathrm{R}^{2}=0.91\right)$

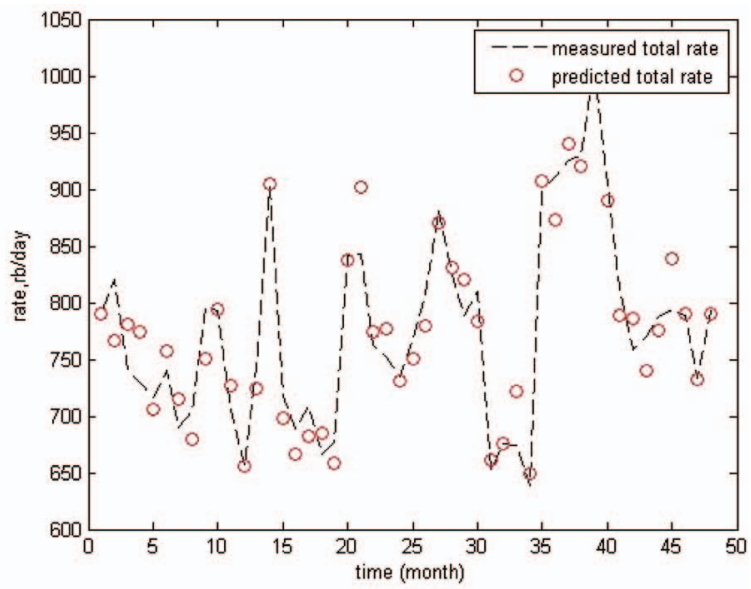

Window $2-2^{\text {nd }}$ period $\left(\mathrm{R}^{2}=0.95\right)$

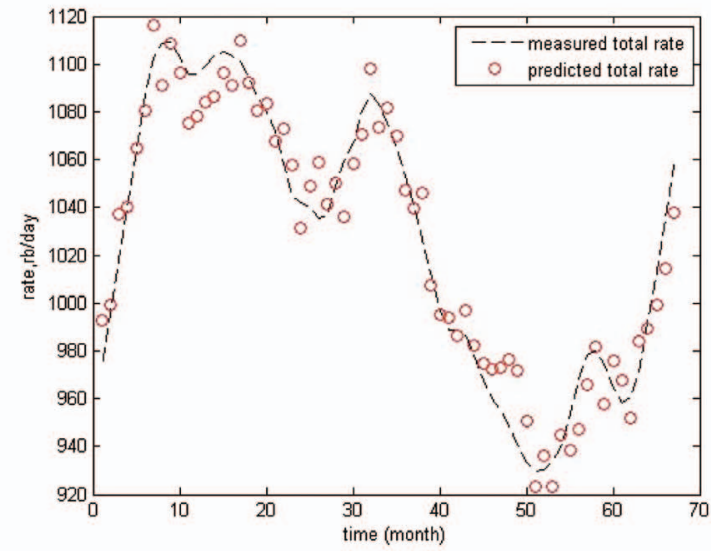

Window $2-3^{\text {rd }}$ period $\left(\mathrm{R}^{2}=0.89\right)$

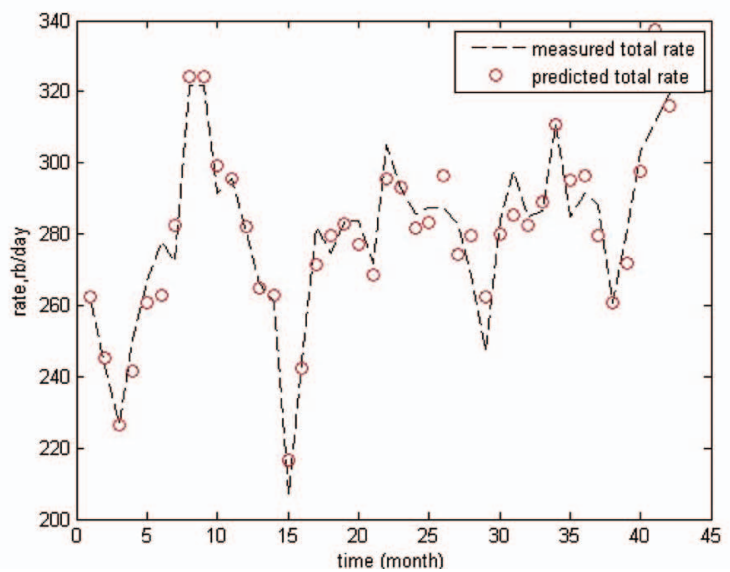

